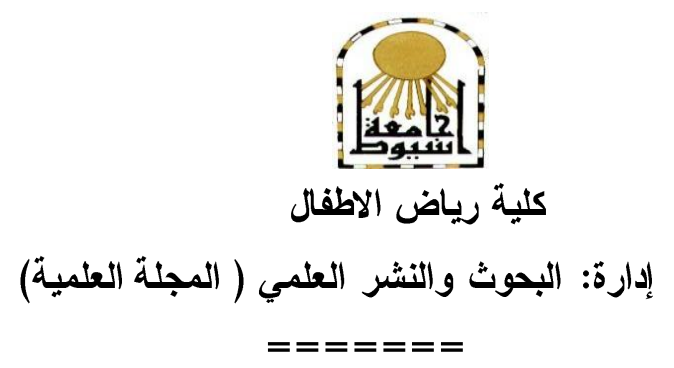

\title{
فاعلية برنامج وسائط متعددة لتنمية ثقافة أطفال الروضة حول بعض المهن اليدوية و تعديل اتجاهاتهم نهوها
}

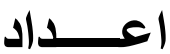 \\ د/ رانيا مممد نبيل هسن الجندي \\ د / ريهام رفعت هممد الايهي \\ مدرس بقسم العلوم التربوية ووكيل كلية \\ استاذ مساعد بقسم العلوم التربوية

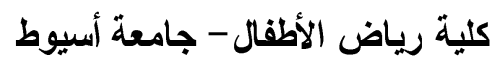 \\ رياض الأطفال - جامعة أسيوط
}

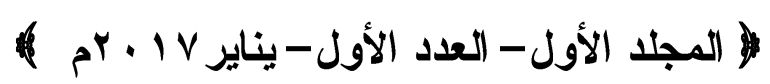


د / ريـهام رفعت محمد المليجي مدي

فاعلية برنامج وسائط متعدة لتمية ثقافة أطفال الروضة د/ راتيا محمد نبيل حسن الجندي

\section{ملخص البحث}

هدف البحث الحالي إلى دراسة فاعلية استخدام برنامج وسائط متعددة لتتمية نقافة الأطفال حول بعض المهن اليدوية و تعديل اتجاهاتهم نحوها .

و اشتملت مجموعة البحث على . ب طفلاً وطفلة من المقيدين بالمستوى الثاني

بمرحلة رياض الأطفال بإدارة أسيوط التعليمية .

وقد استخدمت الباحثتان برنامج وسائط متعددة اشتمل على بعض الأنشطة مثل الالعاب و البطاقات المصورة و المجسمات و القصص الالكترونية والكتب التقاعلية و الانانشيد و الرسم

و التلوين وألعاب البازل و كوتشينة المهن و لعب الادوار والرسوم الثابتة و المتحركة .

ونم استخدام الأنشطة السابقة لتتمية نقافة الاطفال عينة البحث حول بعض المهن

اليدوية وعددها r ا مهنة و كذلك الأدوات المستخدمة في كل مهنة و أيضا أماكن ممارستها ،

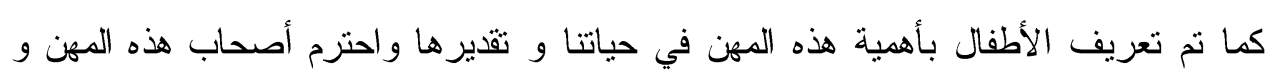

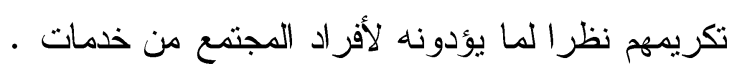

وقد أعدت الباحثتان اختبار ثقافة المهن اليدوية المصور و مقياس اتجاه الأطفال

نحوها ، وتم التأكد من صدقها وثباتهما ، وتم تطبيقهما مرتين على الأطفال مجموعة البحث ( قبلياً وبعدياً ) ، وأوضحت النتائج وجود فرق دال إحصائياً بين متوسطي درجات الأطفال مجموعة البحث لصالح التطبيق البعدي في كل منهما ، كما بينت النتائج أن حجم الأثر الناتج عن استخدام البرنامج في تجربة البحث كان كبيراً ، مما يؤكد فاعليته في تتمية ثقافة المهن

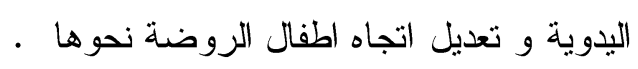

الكماث المفتاحية :

$$
\text { برنامج وسائط متعدة - ثقافة الطفل - المهن اليدوية - الاتجاه . }
$$




\title{
المجلة العلمية لكلية رياض الاطفال - جامعة اسيوط
}

\begin{abstract}
The present research aimed at studying the effectiveness of using a multimedia program for developing kindergarten child culture about some manual crafts and modifying their attitudes towards them.

The research group consisted of 30 male and female KG2 children enrolled in one of Assiut Educational Administration kindergartens.

The researchers used a multimedia program which included some activities such as games, picture cards, corporeal, electronic stories, songs, drawing and painting, puzzles, craft cards, role play, animation and still pictures.

The previous activities have been used for developing the research group culture about some manual crafts (12), as well as the tools used in each craft , places of performing them, in addition to informing children about the importance of these crafts in our life appreciating them, respecting people doing them and rewarding them for their services.

The researchers prepared a manual craft culture pictorial test, and an attitude scale of children towards them. The validity and reliability of the tools have been proved, and they have been pre-and post-administered on the research group. Research results showed a statistically significant difference between the mean scores of research group favoring the posttesting. Also, the results showed a great effect size resulting from using the program, which confirms its effectiveness in developing kindergarten children culture of manual crafts and modifying their attitude towards them.

\section{Key Words:}

Multi-Media Program -Child Culture - Manual Crafts -Attitude

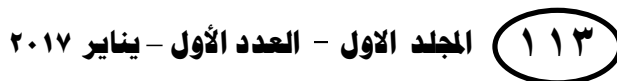


د / ريـهام رفعت محمد المليجي مدي

فاعلية برنامج وسائط متعدة لتمية ثقافة أطفال الروضة د/ راتيا محمد نبيل حسن الجندي

مقدمة :

تشكل النظرة المجتمعية إلى المهن اليدوية مشكلة كبرى، يث ينظرأفراد المجتمع - كباراً كانوا أم صغاراً - إلى المهن اليدوية نظرة دونية لا تتاسب ما يقوم به شاغلوا هذه المهن من عمل شريف يسهم في نمو المجتمع والارتقاء بهاه ، وينسى من لديهم هذه النظرة أن الأنبياء و الرسل اثتنل بعضهم بها ، وضربوا لنا المثل والقدوة في الكفاح من أجل لقمة العيش فكان منهم الحطاب والحداد وراعى الغنم، وكان كل منهم يأكل كما ورد في الأثر من عرق يده.

وانتقلت هذه النظرة إلى أطفال الروضة فأصبح الكثيرون منهم ينظرون إلى الطبيب مثلا نظرة تقدير بينما ينظرون إلى عمل الممرضة نظرة استخفاف وعدم تقدير ، وتمتذ هذه النظرة إلى الفران و عامل النظافة و النجار و الحداد و المزارع وغيرهم. ولعل الأسباب المسئولة عن تلك النظرة ، من وجهة نظر الباحثتين - تعود إلى نقص الوعى لدى أطفال الروضة بهذه المهن ونقص ثقافتهم العامة حولها واعتقادهم بأنها أقل أهمية من المهن ذات العائد المادي المرتفع أو المهن ذات المكانة الاجتماعية العالية. وقد نتج عن هذه النظرة تشكيل اتجاه سلبى نحو المهن اليدوية لاى أطفال الروضة - منلما هي عند الكبار الذين ينقصهم الوعى بأهمية المهن اليدوية في المجتمع- . وقد دفع ذلك طلاب الفرقة الر ابعة - شعبة العلاقات العامة سبقس الإعلام بكليــة الآداب جامعة حلوان ، إلى تتظيم حملة توعية ضمن أنشطة مشروع التخرج الخاص بهــ و المســى " بتكملني "، وكان هدف الحملة نشر ثقافة المساواة بين المهن المختلفة دون تمييز أو تقرقة بـين مهنة وأخرى وأن يعرف أفراد المجتمع أن لكل مهنة أهميتها في حياتتا ، و أنه لا يجب أن ننظر

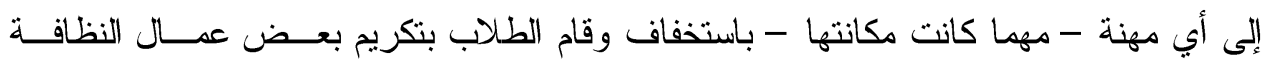

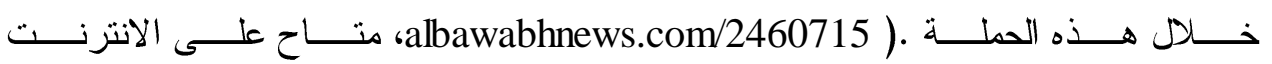

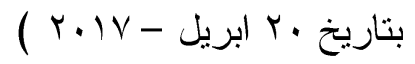
وتمثل التنمية التقافية أداة أساسية لبناء شخصية الطفل حيث يرى لندبرج Lundberg أن اصطلاح الثخصية يشير إلى العادات والاتجاهات والسمات الاجتماعية التي تميز سلوك الفرد والتي يكتسبها عن طريق الاتصال الاجتماعي ، كما أن التتمية التقافية تكسبه للطفل من ولن 


\section{المجلة العلمية لكلية رياض الاطفال - جامعة اسيوط}

قيم ، نساعده على تحديد أهدافه واتجاهاته ، فالاتجاهات وهى ميول للثعور أو الاحساس

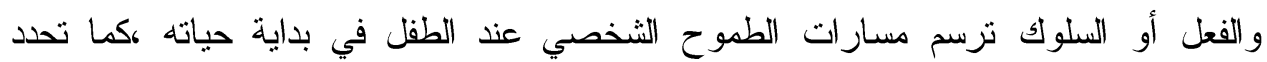

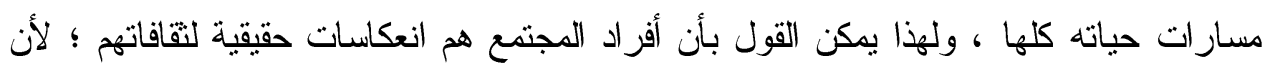

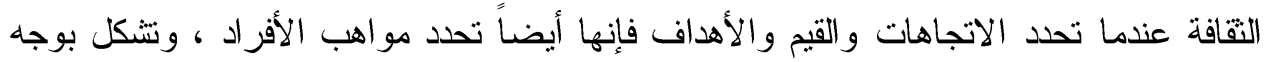

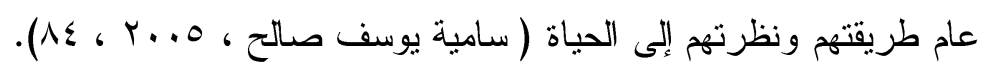
ويعد مجال العمل من أكثر المجالات التي لفتت نظر علماء الاجتماع والاقتصاد وعلم

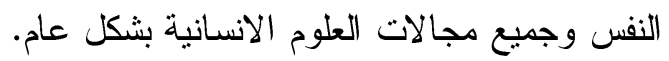

وظهرت كثير من الدراسات التي أهتمت بالتطلعات المهنية لدى الصغار ، أو بالأعمال

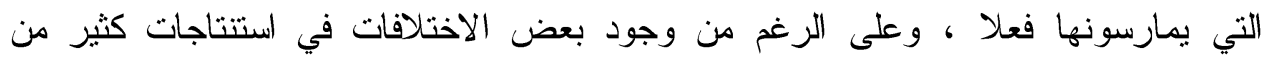
الدراسات التي اهتمت بالطموح المهني للأطفال، أو ما يسميه بعض ولئ الباحثين التطلعات المهنية ؛ فإن أغلب تلك الدراسات تشير إلي أن الصغار غالبا يكونون كثير ا من نطلعاتهم و طموحاتهم

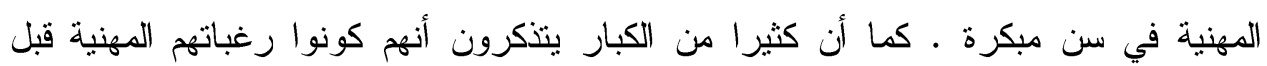
أن يصلوا إلي سن الثالثة عشرة كما أن كثيرا منهم النحق بالعمل نفسه الذي كان كنان يحلم به في صغره ، أما الدراسات الاجتماعية في مجال الاختيار المهني أو الطموح

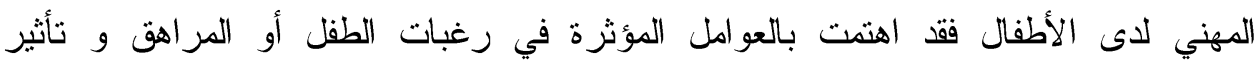

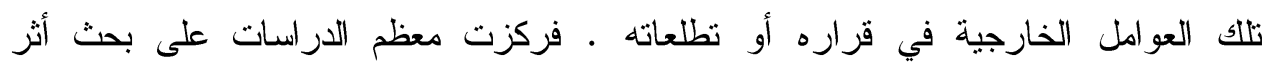

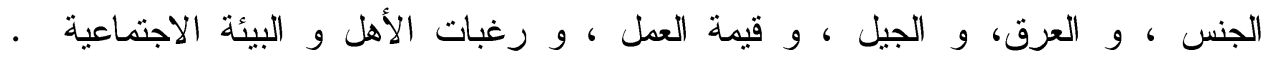

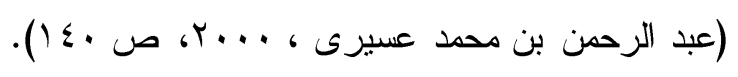

ومن الكتب المصرية البارزة في مجال المهن كتاب ( علي محي الدين راثند ، با. ب ) )

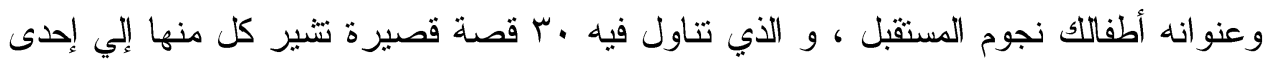

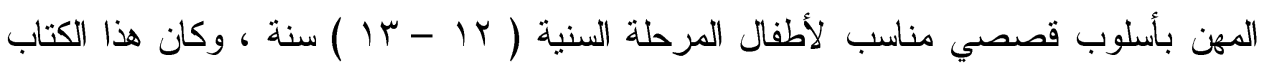

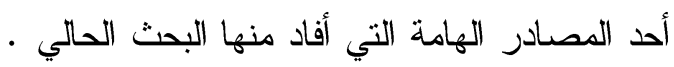

وفي هذا الإطار فإن النظرة نحو المهن و أهميتها تبدأ مع مرحلة الطفولة ، فالطفولة

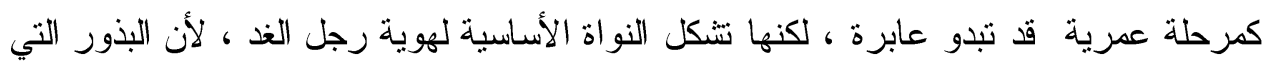
يتم زرعها في هذه المرحلة هي التي سوف تثمر في المستقبل ، مكونة النسق القيمي والثقافي

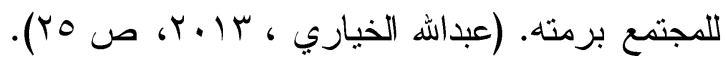


د / ريـهام رفعت محمد المليجي مدي

فاعلية برنامج وسائط متعدة لتمية ثقافة أطفال الروضة د/ راتيا محمد نبيل حسن الجندي

وفي ظل تفجر المعرفة والمعلومات أصبح استخدام الحاسب الآلي في العديد

من المدارس - وعلى وجه الخصوص في برامج رياض الاطفال - مسالة تهم العديد من

التربويين والآباء ـ لذا يجب العمل على استثارة هؤلاء الاطفال ونتويقهم باستخدام مثيرات سمعية وبصرية وحركية لمساعدتهم على التركيز والانتباه حتى تساعدهم على التعلم الجيد ويتحقق ذلك عن طريق استخدام الوسائط المتعددة في تعليم اطفال مرحلة الروضة ، و أكد ذلك ولك

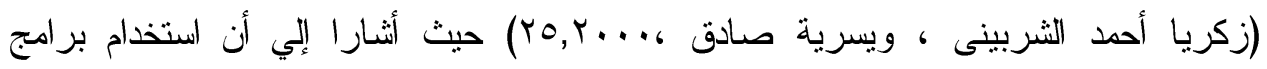
الحاسب الآلي يزيد من انتباه الاطفال، ويساعدهم على اكتساب العديد من المعلومات التي تساهم في تشكيل فكرهم و تقافتهم.

ومن هذا المنطلق تم التفكير في دراسة فاعلية برنامج وسائط متعددة لتنمية ثقافة أطفال

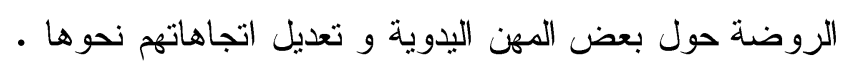
مشكية البصث: :

تحث الاتجاهات الحديثة في التنمية على ضرورة تقديم برامج توعوية متخصصة

تهدف إلى تتمية الوعى التربوي لاسيما في مجال تثقيف الطفل من خلال أنشطة تدريبية

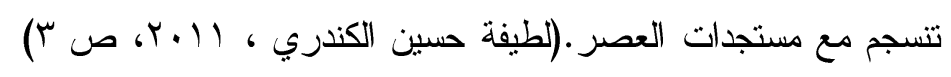
وتعد ثقافة طفل الروضة من الموضوعات الحيوية التي تحظى باهتمام بالغ من التربويين والقائمين على شئون الطفولة ، ومن هنا تكون انطلاقة المجتمع عندما تتضافر بـون الخطط و البرامج التعليمية و النقافية و التزبوية لصالح الطفل من خلال تثقيفه ، ولكي نحقق ذللك يجب أن تتعدد مجالات ثقافة الطفل و تشتمل على جميع الجوانب المرتبطة بحياته و بجميع قطاعات الحياه و مختلف جوانب المعرفة ، على أن تسير عملية التقيف في اتجاه يو اجه منطلبات الطفل ، ليس فقط في مرحلة طفولته ، و إنما أيضا متطلباته التي ستظهر في

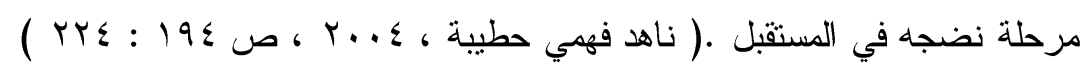
وبالرغم من أهمية التتمية التقافية لطفل الروضة إلا أنه مازال هناك وحتى اليوم قصور واضح في تتقيف أطفال الرياض حول بعض المهن اليدوية و الحرفية و كذلك نظرة

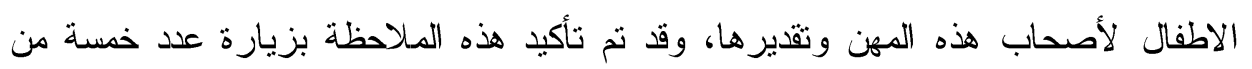
روضات المدارس ( بمدينة أسيوط ) وملاحظة الأشطة المستخدمة في تعريف الاطفال هاب هاب بالمهن اليدوية و الادوات الخاصة بها و تقدير أصحاب هذه المهن ، وقد اقتصر دور معلمات

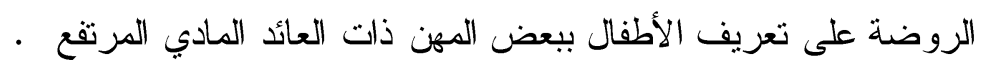


كما لاحظت الباحثنان ندرة الدراسات العربية الني تناولت المهن اليدوية و تعريفها للأطفال وتعديل اتجاهاتهم نحوها ، و لم يتم إدراج وحدة عن المهن في مناهج رياض لأل الأطفال

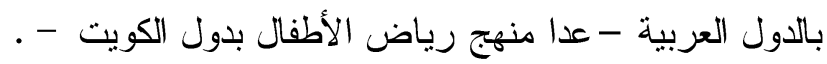

كما تم تطبيق اختبار أولي للتعرف على ددى ثقافة الأطفال حول بعض المهن اليدوية و قياس اتجاهاتهم نحوها، وأكلت نتائجه ضعفاً واضحاً في مستوى الأطفال في هذه المرحلة. من هنا تحددت مشكلة البحث في انخفاض مستوى ثقافة الأطفال حول بعض المهن

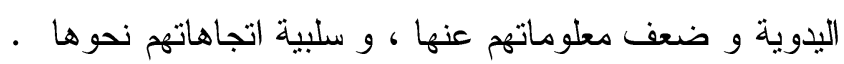

أسئلة البحث:

للتصدي لمشكلة البحث حاولت الباحثتان الإجابة عن السؤال الرئيس التالي: - - ما فاعلية استخدام برنامج متعدد الوسائط لتتمية نقافة أطفال الروضة حول بعض

المهن اليدوية و تعديل اتجاهاتهم نحوها ؟

و يتفرع من هذا السؤال الأسئلة الفرعية التالية :

ما المهن اليدوية اللازم تتمية نقافة أطفال الروضة حولها ؟

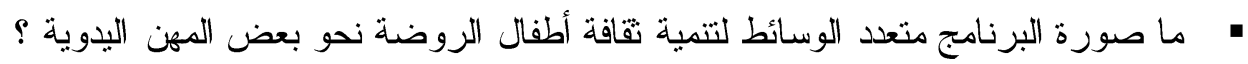

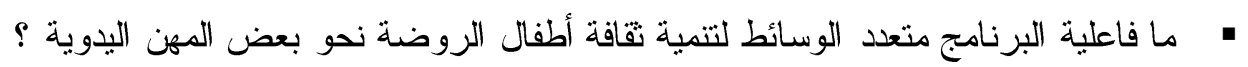

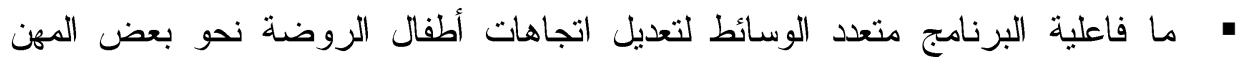

$$
\text { أهداف البحث: اليدوية؟ ماعثة ليرنايج }
$$

- تعرف فاعلية استخدام برنامج متعدد الوسائط لتتمية تقافة أطفال الروضة نحو بعض

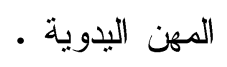

- تعرف فاعلية استخدام برنامج متعدد الوسائط في تعديل اتجاهات الأطفال نحو بعض الأل

$$
\text { المهن اليدوية . }
$$


د / ريـهام رفعت محمد المليجي مدي

فاعلية برنامج وسائط متعدة لتمية ثقافة أطفال الروضة د/ راتيا محمد نبيل حسن الجندي

أهمية (لبحث:

تتضح أهية البحث الحالي فيما يلي:

الأهمية (النظريـة :

- - يلفت البحث نظر أطفال الروضة الي بعض المهن اليدوية المهمة في حياتتا و التي لا

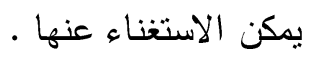

- - يقام البحث عددا من أنشطة الوسائط المتعددة التي يمكن أن نسهم في تتمية ثقافة بعض

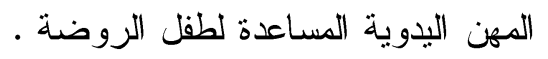

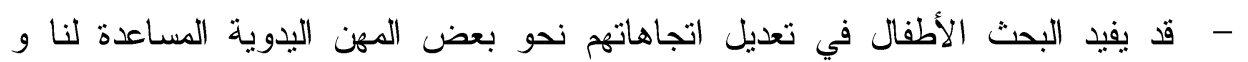

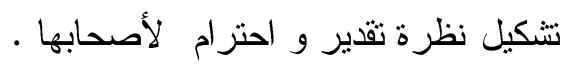

الأهمية التطبيقية :

- لفت انظار المعلمات لتعريف الاطفال ببعض المهن اليدوية الاخرى المهمة - غير

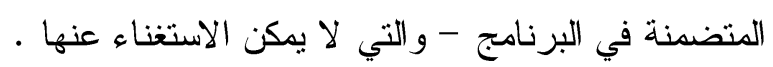

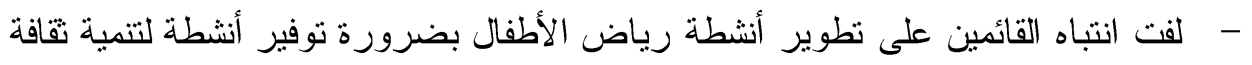
الاطفال نحو المهن اليدوية و الحرفية و تعديل نظرة الاطفال نحوها مصطات البحث:

الوسائط المتعددة : - الو

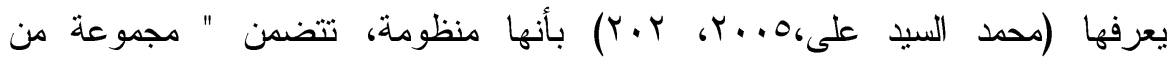

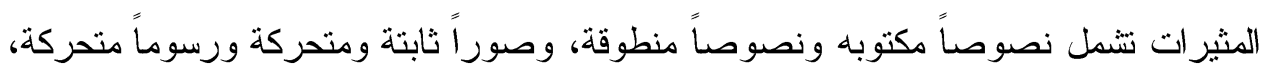
ومؤثرات صوتية متكاملة ومتفاعلة معا وتعمل في نسق واحد، يستهدف نزويد المتعلمين

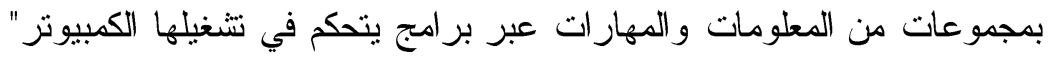
وتعرف الباحثتان الوسائط المتعدة إجرائيا بأنها مجموعة من الأنشطة المعدة لتنمية

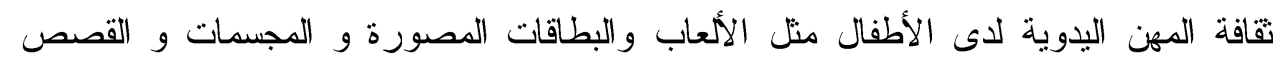

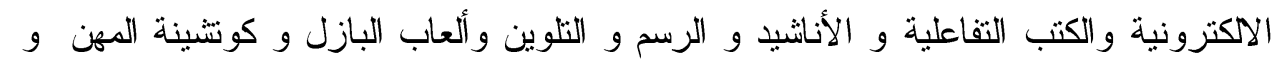

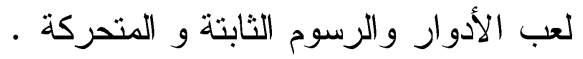




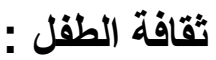

تعد نقافة الطفل احدى الثقافات الفرعية في أبي مجتمع ، وتنفرد بمجموعة

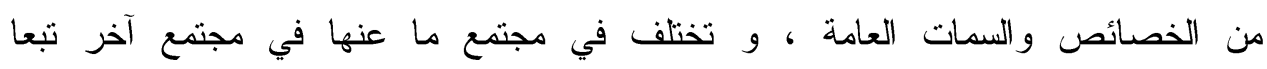

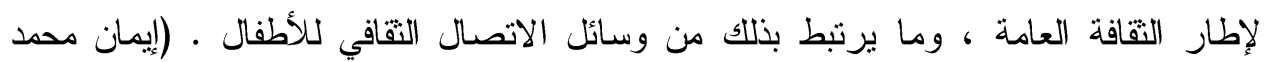
طيور ، +. (r. (r)

وتعرف الباحثتان تقافة الطلل إجرائيا بأنها مجموعة المعارف والمفاهيم و المعلومات

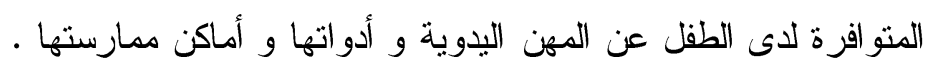

المهن اليدوية :

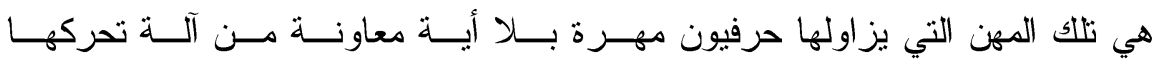

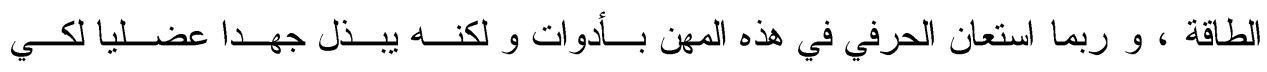

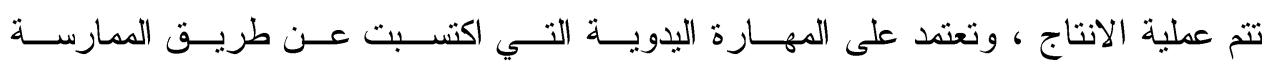

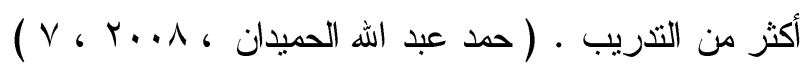

وتعرف الباحثتان المهن اليدوية اجرائيا بأنها بعض المهن التي يتم أداؤها يدوياو تعتدد

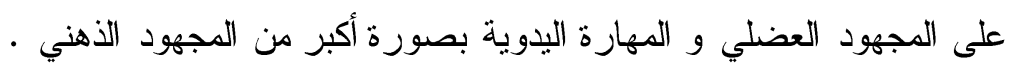

الاتجاه :

يعرف الاتجاه بأنه مجموع ما يشعر به الفرد نحو موضوع معين شعورا إيجابيا أو سلبيا

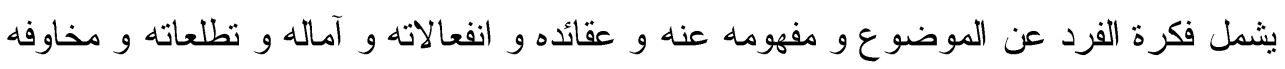

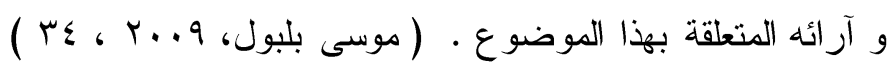

وتعرف الباحثتان الاتجاه إجرائيا بأنه مجموع استجابات الأطفال عينة البحث على مقياس

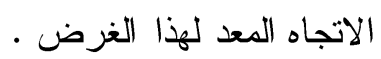


د / ريـهام رفعت محمد المليجي مدي

فاعلية برنامج وسائط متعددة لتنمية ثقافة أطفال الروضة د/ رانيا محمد نبيل حسن الجندي

حدود البحث:

تحدد البحث التالمي بالحدود التالية :

- الحدود البشرية : مجموعة من أطفال المستوى الثاني من رياض الأطفال kg2 المقيدين

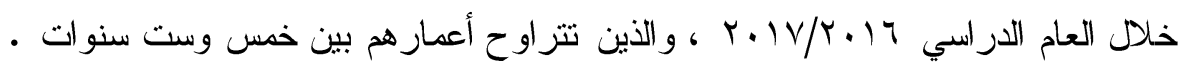

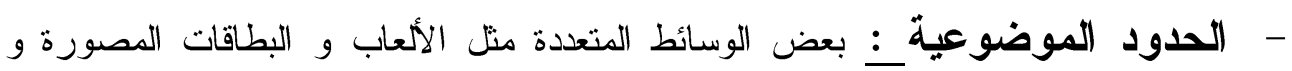
المجسمات و القصص الاكترونية و الأناثيد و الرسم و التلوين وألعاب البازل و كونتثينة

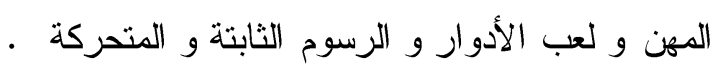

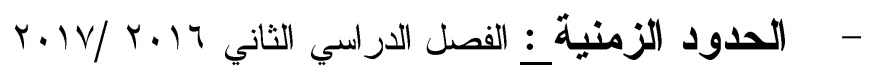
منهج البحث:

نظراً لطبيعة البحث الحالي استخدت الباحثتان المنهج شبه التجريبي (بمجموعة تجريبية واحدة و قياسين أحدهما قبلي و الآخر بعدي).

خطوات البحث و إجراء(ته:

أولاً - للإجابة عن السؤال الأول والأي نصه ما المهن اليدوية اللازم تتمية ثقافة أطفال

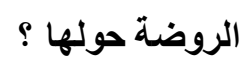
قامت الباحثثان بما يلي: - - مراجعة الكتابات والأدبيات التربوية التي تتاولت المهن اليدوية .

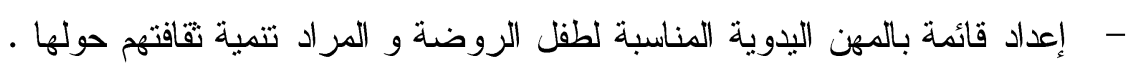
- - عرض القائمة على المتخصصين في مجال رياض الأطفال.

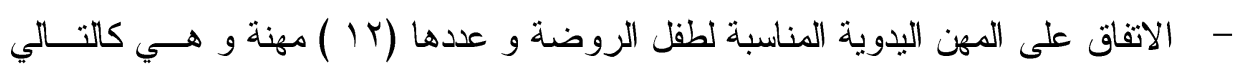

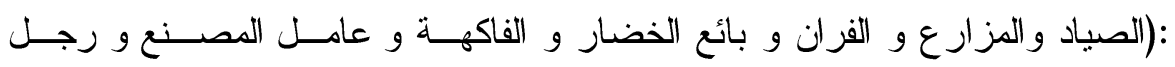

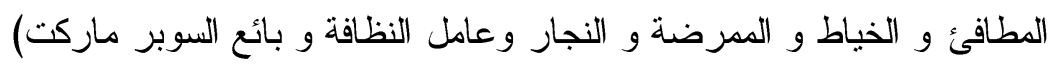

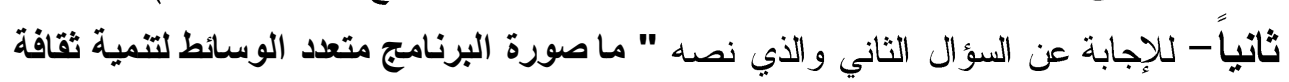

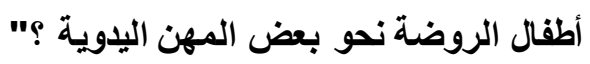




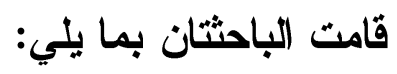

- - مراجعة الكتابات والأدبيات التزبوية التي تتاولت الوسائط المتعددة .

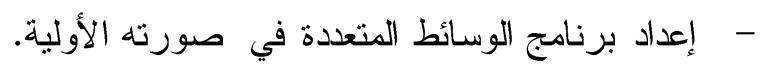
- - عرض البرنامج على متخصصين في مجال تكنولوجيا التعليم ورياض الأطفال.

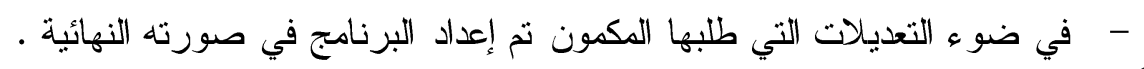
ثالثاً: إعداد أدوات القياس:

قامت الباحثتان بإعداد أدوات القياس التالية:

- - اختبار نقافة المهن اليدوية المصور • ( إعداد الباحثتين )

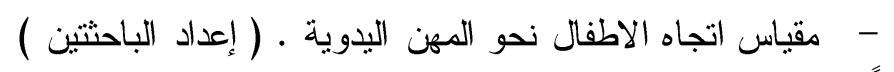
رابعاً - اختيار مجموعة البحث: الجياه

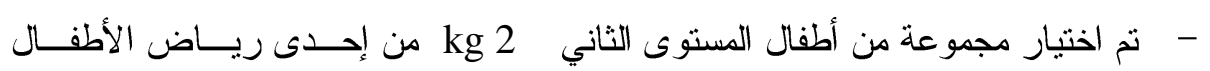

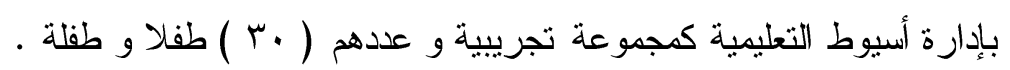

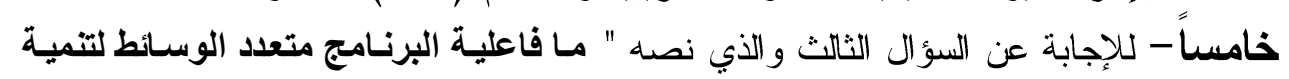
ثقافة طقل الروضة نحو بعض المهن اليدوية ؟" نم القيام بالخطوات التالية:

o النطبيق القبلي لاختبار تقافة المهن اليدوية المصور على مجموعة البحث.

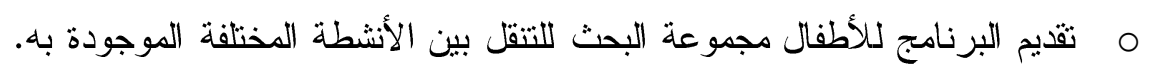

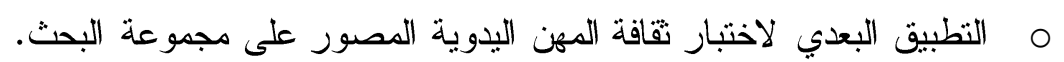
م رصد النتائج وتحليلها إحصائياً. سادساً - للإجابة عن السؤال الرابع و الذي نصده " مـا فاعلية البرنـامج متعدد الوسـائط لتعديل اتجاهات أطفال الروضة نحو بعض المهن اليدوية ؟ب بل نم القيام بالخطوات التالية: o التطبيق القبلي لمقياس اتجاه الاطفال نحو المهن اليدوية على مجموعة البحث.

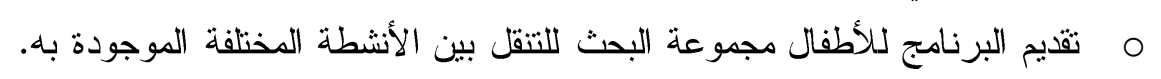
o التطبيق البعدي لمقياس اتجاه الاطفال نحو المهن اليدوية على مجموعة البحث. o رد النتائج وتحليلها إحصائياً. 
د / ريـهام رفعت محمد المليجي مدي

فاعلية برنامج وسائط متعدة لتمية ثقافة أطفال الروضة د/ راتيا محمد نبيل حسن الجندي

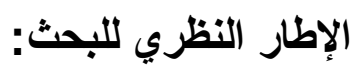

Multimedia : أولا : الوسائط المتعددة

تشهم الوسائط المتعددة في إثارة اهتمام الطفل عن طريق تقديم أثكال متتوعـــة منهــا، حيث تعمل هذه الوسائط على استثارة أكثر من حاسة لدى الطفل مما يؤدى الى زيـــادة اهتمامـــه

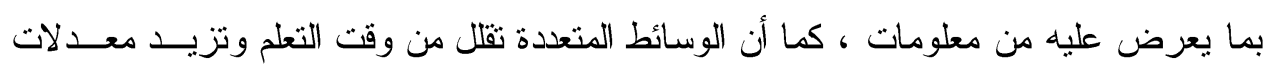
الاحتفاظ به.

\section{تطور مفهوم الوسائط المتعددة :}

تعددت التعريفات الخاصة بمصطلح الوسائط المتعدة Multimedia ، ففي البدايات المبكرة لهذا المصطلح كانت تعرض في المتاحف و المعارض وسائل بصرية ، وأيضاً تقدم عروض لوسائل متعددة تحتوي على العينات و النماذج المجسمة والصور المرسومة والثرائح الضوئية والأفلام الثابتة، ثم استخدام أسلوب المزج بين المواد التعليمية المرئية

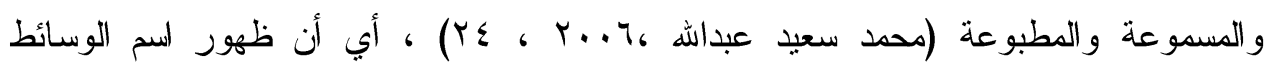
المتعددة جاء ليدل على عرض الوسائط بشكل متزامن باستخدام أكثر من وسيلة. وقد مر مفهوم

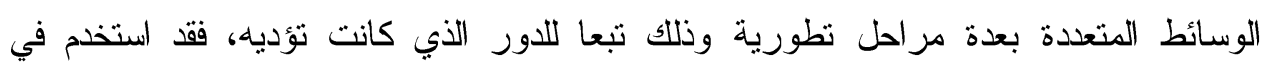
البداية لوصف عروض الثرائح الضوئية Slides المصحوبة بالصوت وانتشر المصطلح لدى المتاحف و المعارض التي أنشأت قاعات خاصة لعرض الوسائط المتعدة على زوارها

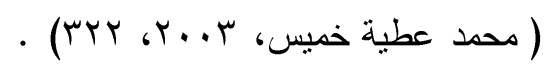

وقد تعددت محاو لات الباحثين لوضع تعريفات للوسائط المتعدة تعرض الباحثتان بعضا منها فيما يلي :

عرف( الغريب زاهر إسماعيل، ( . ب، ع ج I) الوسائط المتعدة بأنها برنامج كمبيوتز يتكون هن المزج بين النصوص المكتوبة والرسومات والصور ولقطات الفيديو، والمؤثرات الصوتية، والحركية، ومما يتيح للمتعلم التفاعل والتحكم في معلومات البرنامج، الأمر الذي ولي ولتين ينتج عنه عمليات تفكير جديدة لمساعدة المتعلم على التفكير فيما وراء التفكير. 


\section{المجلة العلمية لكلية رياض الاطفال - جامعة اسيوط}

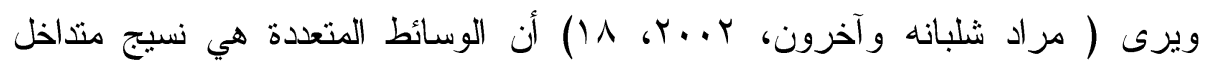

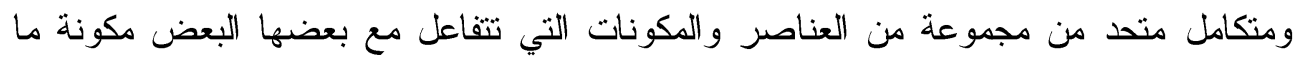

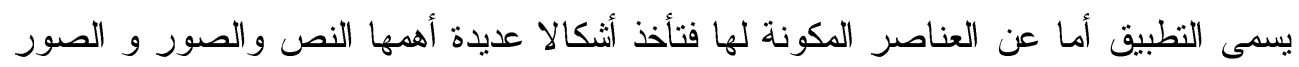
المتحركة و الصوت و الفيديو . لمنئ.

ويرى (Alexander, 2003, 121)، أن برامج الكمبيوتر متعددة الوسائط تمثل تكنولوجيا

عرض وتخزين واسترجاع وبث المعلومات المعالجة آليا بأثنكال متعددة وبطريقة تفاعلية.

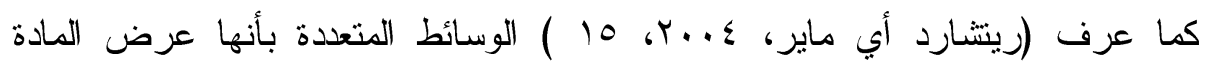

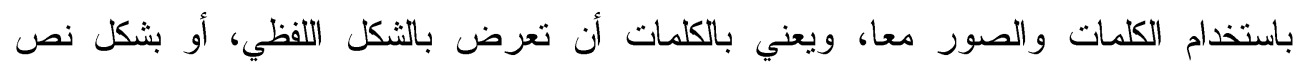

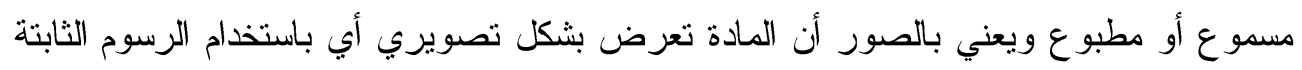

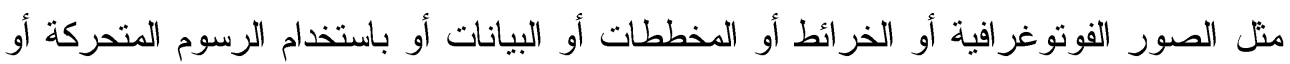
أفلام الفيديو.

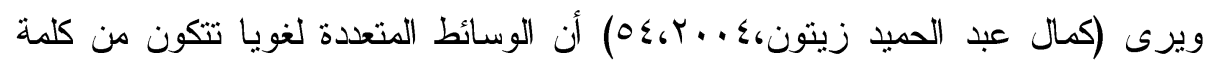

Multi الاتصال متل الصوت والصورة والفيديو بصورة متكاملة من أجل تحقيق التفاعل في عملية

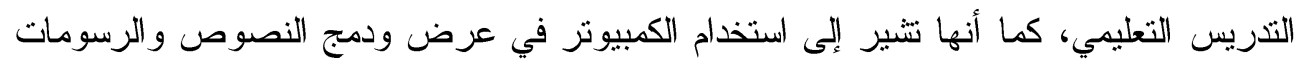
و الصوت والصورة برو ابط وأدوات تسمح للمستخدم بالاستقصاء و التفاعل و الابتكار ، و الاتصال.

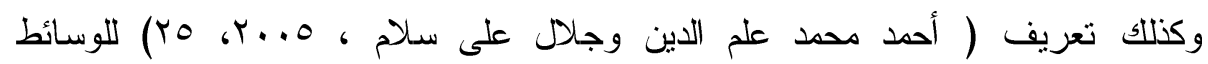

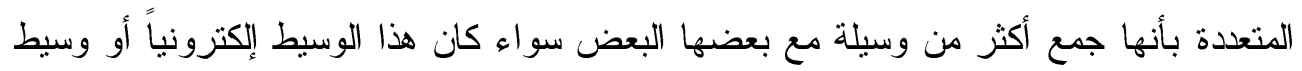

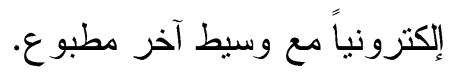

ويعرف وبستر(Webster,1996,835) الوسائط المتعدة بأنها استخدام أكثر من وسيلة

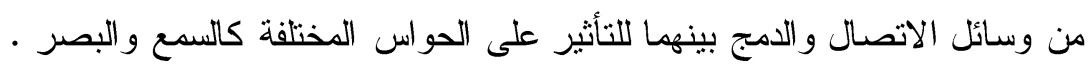
ويرى (Apostolos, S. \& Panagiotis, A, 2005 , 62) أن الوسائط المتعددة التفاعلية هي مزج بين إمكانيات أجزة التشغيل وإمكانيات البرامج المتقدة لإيجاد خليط غني من النص و الجر افيك و الصوت و و التحريك و الفيديو . 
د / ريـهام رفعت محمد المليجي مدي

فاعلية برنامج وسائط متعدة لتمية ثقافة أطفال الروضة د/ راتيا محمد نبيل حسن الجندي

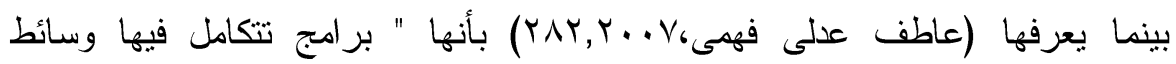
الاتصال بالطفل متضمنة الصوت والموسيقى ، والصور الثابتة والمتحركة، والرسوم الثابتة

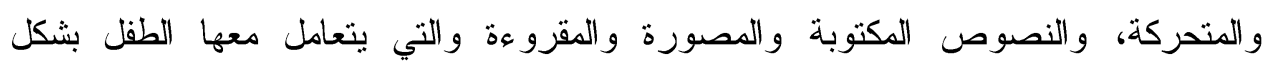
تفاعلي".

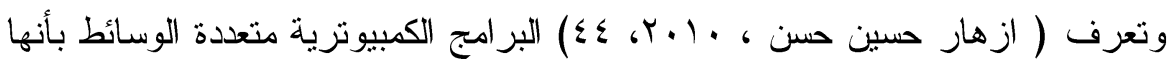
" برامج كمبيوتزية تقدم المادة العلمية عن طريق مزج ثنلاثة أو أكثر من وسائط تقديم المحتوى (النصوص المكتوبة، الكلمات المنطوقة، الموسيقى والمؤثرات الصوتية، الصور و الرسومات الثابتة و المتحركة، لقطات الفيديو الرقمية ، يسهل للمتعلم التحكم فيها و التفاعل معها في إطار من التوافق والتوازن والتكامل فيما بينها ).

ويــري (P1926, M.,2012, Natarajan) الوسائط المتعددة على أنها مزيج من عناصر الصوت ، و الصور ، والصور المتحركة ، و النصوص ، و الفيديو والتفاعلية". (Kimball,J.W.,Kinney,E.M.,Taylor,B.,\&Stromer, R.,2013) ويـرى (ألوسائط المتعددة عمج بين الكمبيوتز و الوسائط لإنتاج بيئة تفاعلية تحوى

$$
\text { النصوص و الرسم و الصوت و الفيديو". }
$$

وعرف (Ptephanie,Fleck,Gilles,Simon,2013 ) P8 ) الوسائط المتعددة بإنها تكنولوجيا الحاسب الآلي التي تدمج (الصور †الصوت-الحركة) في آن واحد مما يجعل تعلم الطفل اكثر واقعية وخاصة في مفاهيم علوم الارض .

ويعرف (Comors,F.,Comors,P.,\&Meyer,C.A.,2016) الوسائط المتعددة على انها "التطبيقات الكمبيوتزية التي تسمح للمستخدم برؤية وسماع الانواع المختلفة من المعلومات عبر شاشة وبمساعدة نظام صوتي".

و التعريفات السابقة تتفق جميعها على أن أهم ما يميز الوسائط المتعددة هي أنها تمكن المستخدم من التفاعل معها على أن يجمع بين هذه الوسائط جهاز كمبيوتر واحد.

ويمكن القول بأن هذه التعريفات نشترك جميعها في نظرتها لبرامج الكمبيوتر متعدة الوسائط من حيث عناصرها المتمنتة في النصوص المكتوبة Texts و الصور الثابتة Still Motion pictures و والرسور المتور المتحركة Animation pictures 


\section{المجلة العلمية لكلية رياض الاطفال - جامعة اسيوط}

والرسوم الخطية Graphics والصوت Sound وتتفق في أن الحد الأدنى يمكن أن يقتصر على عنصرين من هذه العناصر، كما تجمع معظم التعريفات على أن برامج الكمبيوتر متعددة

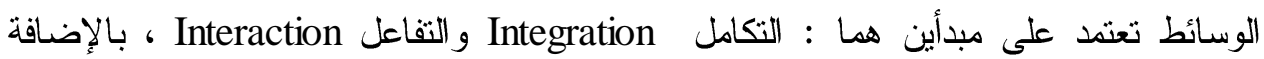

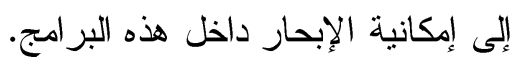

من خلال عرض التعريفات السابقة للوسائط المتعدة يمكن تحليد مكوناتها فيما يلي: المحتوى، الوسط، البرامج، الأجززة، أدوات التوصيل.

أهمية استخدام الوسائط المتعددة :

إن التعليم و التعلم عن طريق برامج الكمبيوتز يهيئان للمتعلم بيئة تعليمية نشطة وتفاعليــة

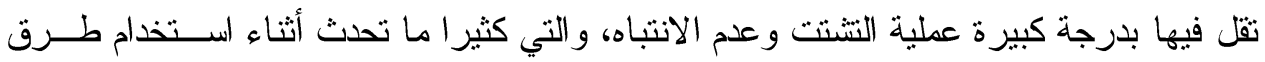

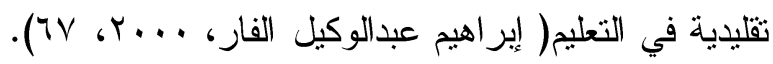

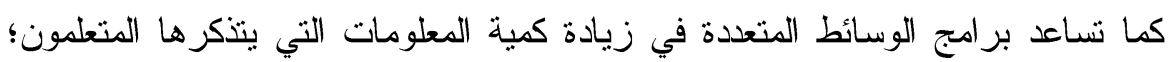

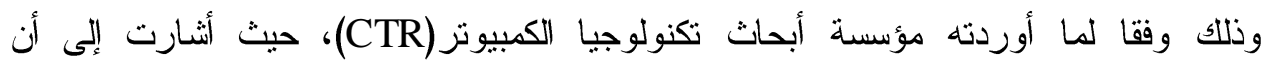

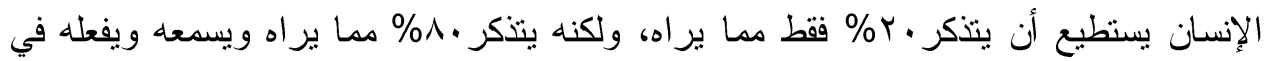
الوقت نفسه وهذا ما تستطيع أن توفره بر امج الوسائط المتعددة

( Fred. T. Hofstetter 2006 )( Miller,2007,p2)

وقد أجمعت الدراسات على أن الوسائط المتعددة لها قدرة كبيرة على تتمية قدرة الطفل على التخيل من خلال استخدام أكثر من حاسة ( Multi - Sensory experience ) مما يثير قدرته على التخيل والابتكار، وتصف ماريا منتسوري الخيال بأنه القوة العظمى لهذه

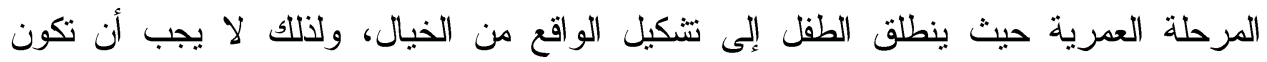

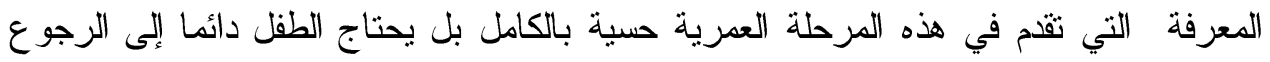

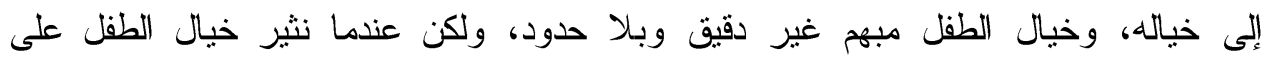

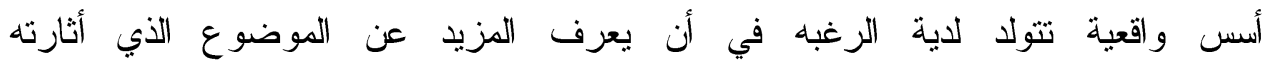

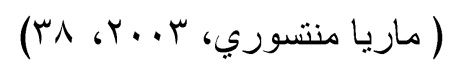


د / ريـهام رفعت محمد المليجي مدي

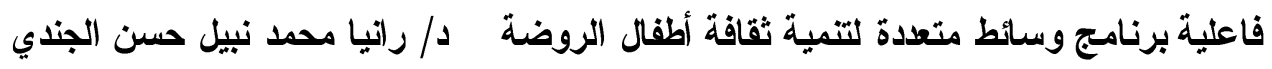

أهمية الوسائط المتعددة لطقل الروضة :

تؤدي برامج الكمبيوتز دورا مهما وفعالا في مرحلة الروضة من حيث قدرتها على

تنمية المفاهيم المرتبطة بالمرحلة على كافة مستوياتها، كما أنها تساعد على اكتساب الطفل لأسلوب حل المشكلات من خلال ممارسته لبعض الأنشطة والألعاب التعليمية، الأمر الذي يساعد على تتمية مداركه وتزويده بدائرة معلوماتية قلما تتوافر له عن طريق وسائل أخرى

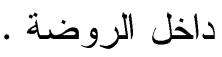

ويرى ( Meckes, S. 2004,1237) أن استخدام برامج الكمبيونز في التعليم في

مراحل الطفولة المبكرة يؤدي إلى تطوير النواحي الإدراكية للأطفال كما أنثارت أيضا دراسة " شيرلي (Shirley A.Mecke,2004,136) إلي أهمية استخدام برامج الكمبيوتر كأنشطة إضافية مع طفل الروضة؛ حيث يمكن أن تزيد وتحسن من تعلم الأطفال .

وتسهم برامج الوسائط المتعدة بكفاءة عالية في تتمية مفاهيم الطفل حول الأسس و العناصر المتواجدة في بيئته وإدراك العلاقات بينها، منل القدرة على إدراك الثكل والحجم و اللون وعلاقات التضاد Opposites وعلاقات التناظر Matching والتذكر Memory، وتسهم برامج الوسائط المتعدة أيضا بشكل ملحوظ في تتمية مناشط الطفل المرتبطة بعلاقات التصنيف والترتيب وإقامة العلاقات الكمية وتقدير الاحتمالات والتكافؤ بين العناصر وكلها مهارات تتميها برامج الوسائط المتعددة عن طريق الممارسة، الأمر الذي يعمق تلك المفاهيم

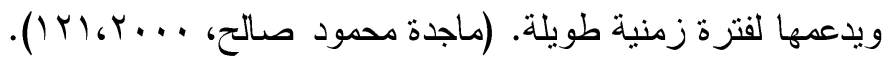

كما تعمل برامج الوسائط المتعددة على تتمية قدرة الطفل على التمبيز البصري والتآزر اللفظي والبصري (Verbal \& Visual Learning)، حيث تتم الاستجابات عند

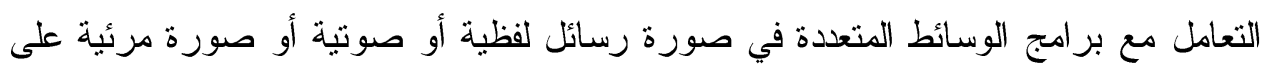

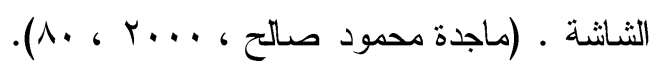

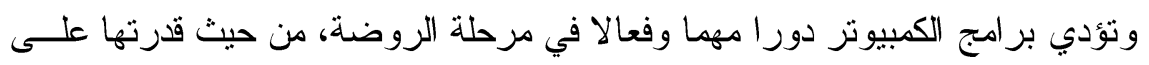

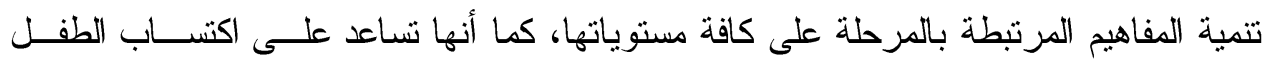

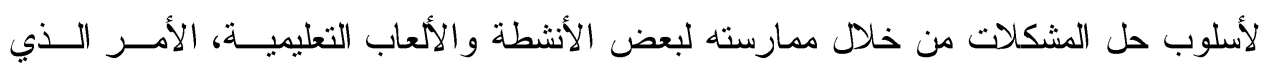

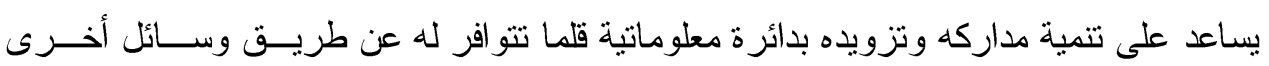
داخل المرحلة التعليمبة. 


\section{المجلة العلمية لكلية رياض الاطفال - جامعة اسيوط}

ويرى ( Stephen Plow Man,2003 P 149:p 199 أن استخدام برامج الكمبيوتز في التعليم في مراحل الطفولة المبكرة يؤدي إلى تطوير النواحي الإدراكية للأطفال. وقد أنشارت ايضا دراسة (Meckes, S. 2004 ) إلي أهمية استخدام برامج الكمبيوتر كأنشطة إضافية مع أطفال مرحلة الطفولة المبكرة حيث بمكن أن تزيد وتحسن من تعلم الأطفال. وبناء على ما سبق تتفق الباحثتان مع التعريفات السابقة للبرامج الكمبيوترية متعددة

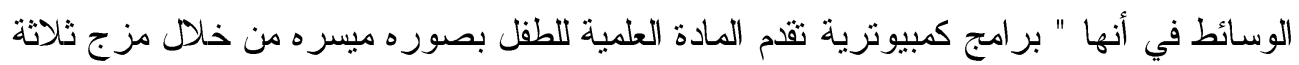

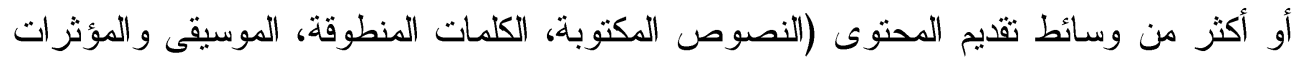

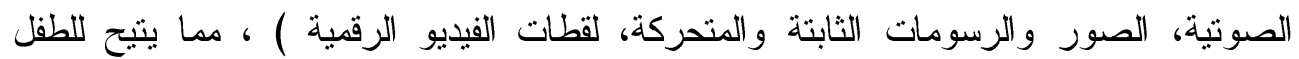

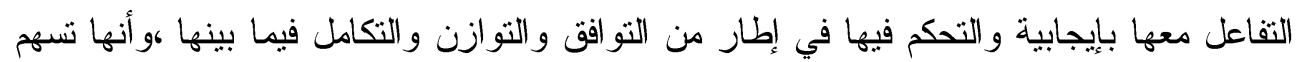
بكفاءة عالية في تتمية مفاهيم الطفل حول الأسس والعناصر المنواجدة في في بيئته وإدراكه للعلاقات بينها ـ لكاءة

ثانيا : ثقافة (لطقل

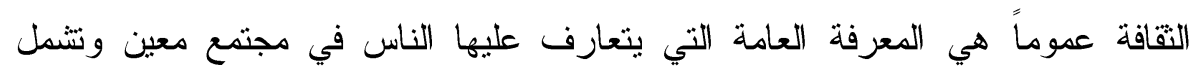

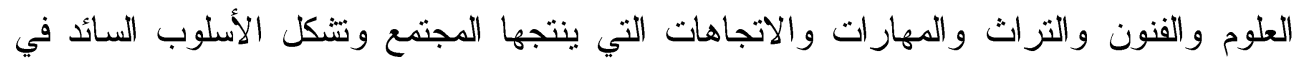
الحياة ، و الطفل المتقف هو الذي ينال نصيبا جيدا من المعارف و العلوم والآداب. وقد عرف حامد عمار النقافة بأنها "جملة الأفكار والمعارف والمعاني والقيم

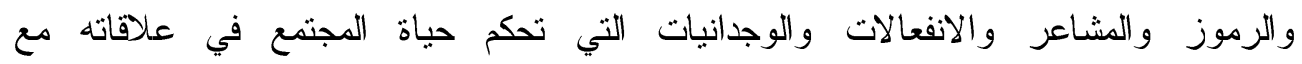

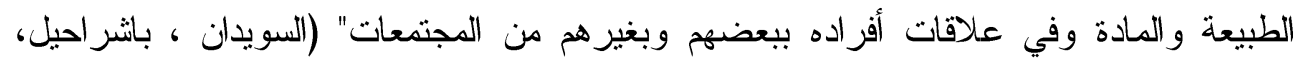

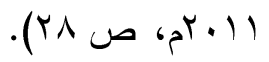

وعلى مستوى نقافة الطفل ، يختلف طفل اليوم عن الطفل في منتصف القرن العشرين فهو

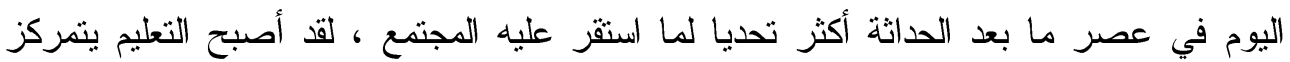
حول الطفل و أصبحت حاجاته من أساسيات التربية. (Ivashkevich, 2009, 55) وتلعب الأسرة دورا محوريا في ثقافة الطفل اذا ما قورنت بغيرها من المؤسسات

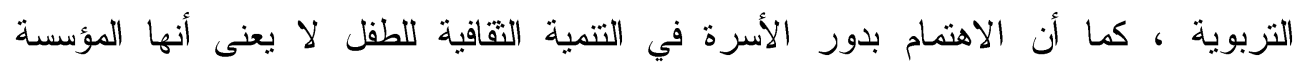

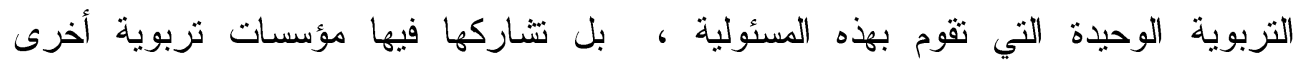

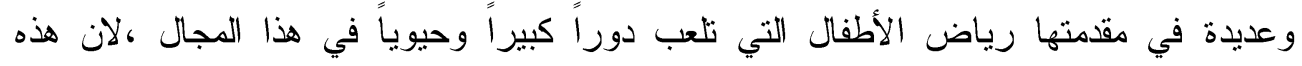

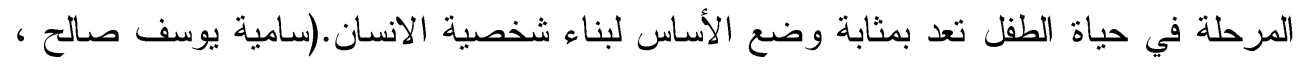

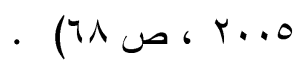


د / ريـهام رفعت محمد المليجي مدي

فاعلية برنامج وسائط متعدة لتمية ثقافة أطفال الروضة د/ راتيا محمد نبيل حسن الجندي

و تقوم رياض الاطفال بدور فعال في نشر الثقافة فهي تترك للطفل الحرية لممارسة نشاطه

كما تعمل على اكتشاف ميوله وقدراته وامكانياته ، و اكتسابه للعديد من المهارات والخبرات

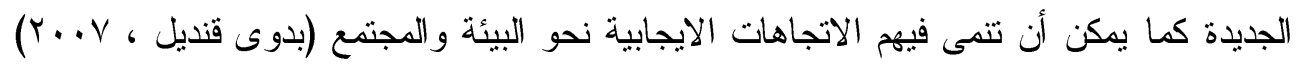

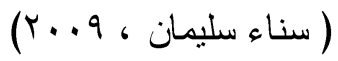

الاسباب التي تحول بين الطفل واكتساب الثقافة:

فيما يلى بعض الأسباب التي تحول بين الطقل واكتساب الثقافة: ( لطيفة الكندرى

$(r \cdot: 196411$

قلة الدافعية لدى الأطفال في اكتساب الثقافة بسبب غياب الوعي لديهم.

ه الجهل بإمكانيات وميول الطفل.

•ابتعاد وسائل الإعلام السمعية و البصرية عن دورها التوعوي و الثقافي.

• الاستغلال السلبي لوسائل التكنولوجية الحديثة (الهواتف النقالة، و الحاسب الآلي....) نتيجة

$$
\text { غياب الوعي التزبوي. }
$$

قلة الاهتمام باللغة العربية؛ فاللغة جسر أساس لبناء التقافة الأصيلة .

ثقافة المهن اليدوية:

المهن اليدوية هي تلك المهن التي يقوم بمزاولتها الحرفي معتمداً في عمله على

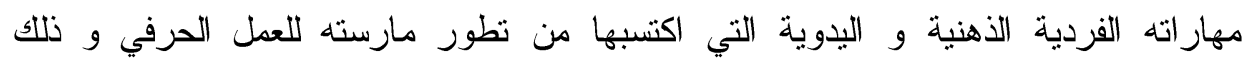

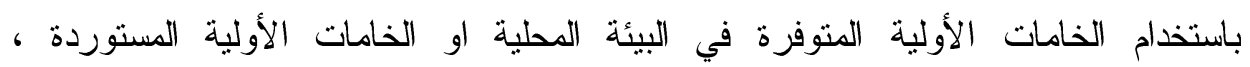
بحيث يتم التعامل معها في الإنتاج بصورة يدوية أو باستخدام بعض العدد و الأدوات البسيطة

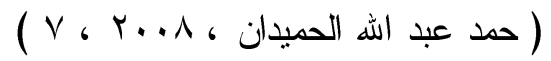

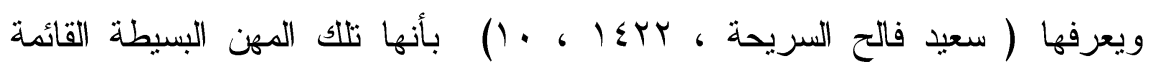

على التكرار و لا تحتاج الي مؤهلات علمية عالية و يمكن للفرد مزاولتها عن طريق الممارسة

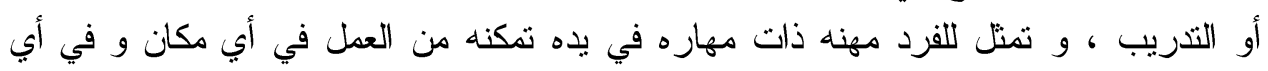
وقت لحسابه او لحساب غيره .

وتعد المهن من أكثر المجالات التي تغيرت تغيراً كبيراً خلال العقود الأربعة الماضية ، والجدير بالذكر أن المهن تتغير من فترة إلى أخرى وفقاً للتغيرات الاجنماعية و الاقتصادية . الا أن سرعة التغير وحجمة يختلفان من فترة إلى أخرى.(عبد الرحمن محمد

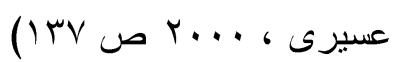




\section{المجلة العلمية لكلية رياض الاطفال - جامعة اسيوط}

ويختلف المدى الذى يحدد المكانة الاجتماعية أو المنزلة الاجتماعية للمهن باختلاف التقافات ، ففي كثير من التقافات تفتقد بعض الأعمال الحد الأدنى من الاحترام والتقدير ، وهذا

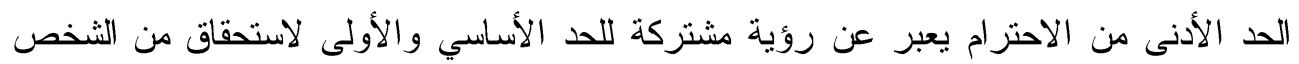

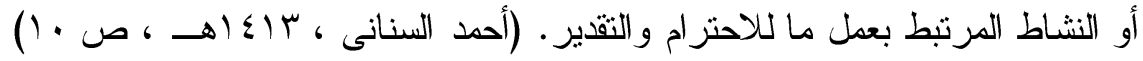

ثالثا: الاتجاه

يمنل الاتجاه حصيلة مكتسبة من الخبرات والآراء و المعتقدات يكتسبها الطفل من البيئة

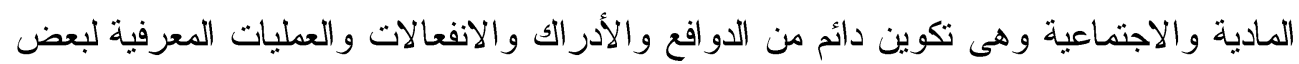

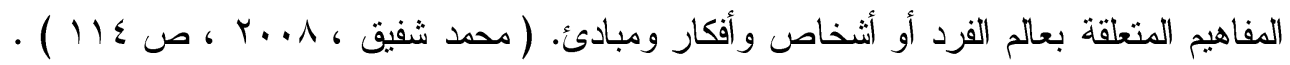
وقد تعددت تعريفات الاتجاه حيث لا يوجد تعريف واحد محدد يعترف به جميع المشتغلين

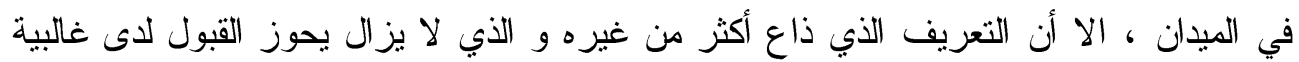

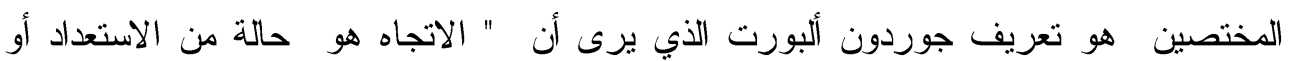

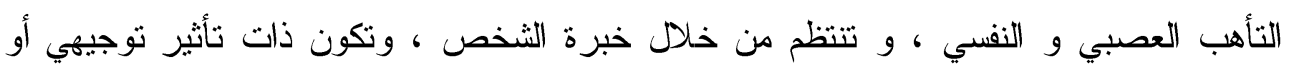
دينامي على استجابة الفرد لجميع الموضوعات و المواقف التي تستثير هذه الاستجابة ". ) ل O,Keefe ,2002:6 )

وتحتل الاتجاهات مكاناً هاماً في تحديد سلوك الافراد ، كما تؤثر فى ادر اكهم للمواقف و الأحداث التي تربطهم بالآخرين ، وفى حكمه على تلك المواقف ، كما أنها تؤثز فى الكفاءة

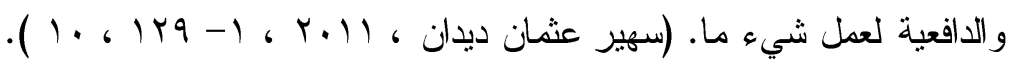

\section{ومن خلال ما سبق يمكن الاتفاق على ما يلي:}

ا- الاتجاه عبارة عن مفهوم فرضى يظهر فى تأثيره على سلوك الأفراد وبالتالي يمكن قياس هذا المفهوم.

ץ- الاتجاه عبارة عن حلقة الوصل بين المثيرات التي يتعرض لها الفرد واستجابة الفرد لهذه المثيرات ، ومن هنا تبرز أهمية الاتجاه في تحديد سلوك الفرد الفرد.

س- الاتجاه يتكون من خلال خبرة الفرد وتفاعله مع المواقف المختلفة مما يشير إلى أنه يمكن

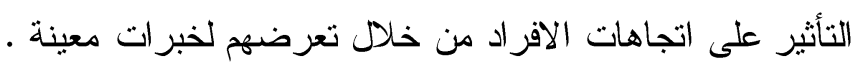

ع - الفرد يكتسب الاتجاهات نتيجة للمو اقف والخبرات التي يمر بها أثناء حياته ، وبقدر ما هاء تحمله هذه الخبرات من مشاعر سارة أو مشاعر مؤلمة تتكون لدى الفرد اتجاهات سلبية

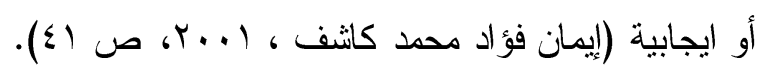


د / ريـهام رفعت محمد المليجي مدي

فاعلية برنامج وسائط متعدة لتمية ثقافة أطفال الروضة د/ رانيا محمد نبيل حسن الجندي رامي

خصائص الاتجاهات:

للاتجاهات خصائص متعدة ولكنها تتضمن دائماً علاقة بين فرد وموضوع من

$$
\text { الموضوعات أهمها: }
$$

1- الاتجاهات مكتسبة ومتعلمة وليست وراثية.

r- ب الاتكون الاتجاهات من فراغ.

r- لاتجاهات خصائص انفعالية.

؟- تتعدد الاتجاهات وتختلف حسب المثيرات التي ارتبط بها.

ه- تغلب على الاتجاهات الذاتية أكثر من الموضوعية من حيث المحتوى.

ج- الاتجاهات محدة وعامة ، وهى استجابة لمنبه أو شيء أو أمر محدد ، وكلما كان المنبه

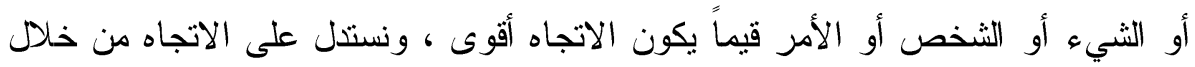
السلوك الظاهر، وتكون الاتجاهات إيجابية في حالة إقدام الفرد على الأشياء أو سلبية في

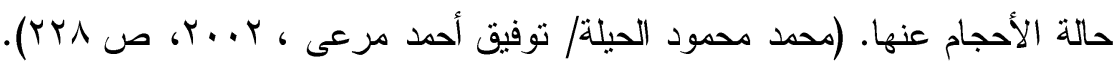

- الاتجاهات لها صفة الثبات النسبي لدى الفرد ، ومن المكن تعريفها و تغييرها تحت

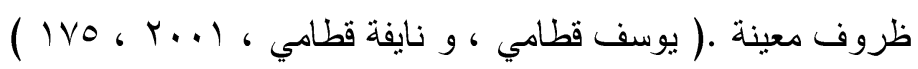

^- قد يقاوم الاتجاه التعديل والتغيير أو قد يكون ضعيفاً يمكن تعديله وتغييره

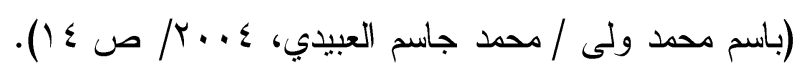

9- الاتجاهات قابلة للملاحظة و القياس و التقدير ويمكن التنبؤ بها.

• 1 - تتكون الاتجاهات من بعدين رئيسين هما البعد المعرفي والبعد الانفعالي.

مما تقدم يمكن القول بأن المدرسة وخاصة الروضة تلعب دوراً هاماً في تكوين الاتجاهات لدى المتعلمين وذلك من خلال تفاعله مع الأقران والمعلمين ، و يعد تأثير الاقران من أهم العوامل التى تساهم فى تشكيل الاتجاهات بعد تأثير الوالدين ، ويتكون هذا التأثير في مرحلة مبكرة من عمر الفرد وكلما تقدم في عمره فإن هذا التأثير يزداد وبشكل أكبر.

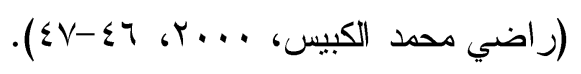




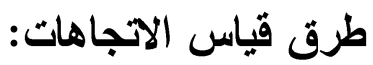

على الرغم من أننا نعلم جميعاً أن الجميع من حولنا يحملون اتجاهات بداخلهم إلا أننا من

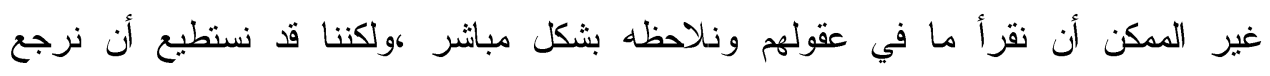

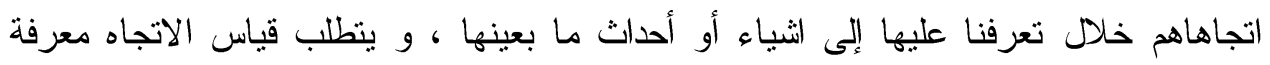

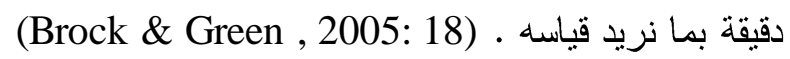

وهناك طريقتان من طرق القياس للاتجاهات :

الطريقة المباشرة في القياس:

وهى عبارة عن مجموعة من الاسئلة التي يتم توجيهها للثخص المر اد قياس اتجاهاته.

الطريقة غير المباشرة:

حيث يتم استتناج الاتجاهات من أدلة أخرى غير الاسئلة المباتشرة ،فالمقاييس الغير

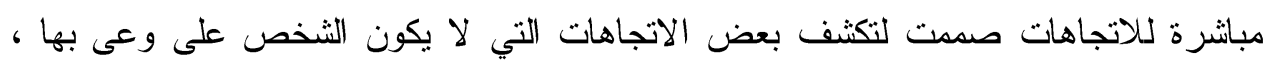

وهى ما تسمى بالاتجاهات الضنية. (Bohner. \& wank e , 2002:19)

ويتبنى البحث الحالي الطريقة المباثرة في القياس نظر المناسبتها لطفل الروضة

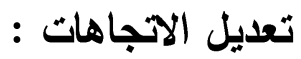

ربما يبدر للوهلة الأولى أن تغيير الاتجاهات أمر بسيط ، و حيث أن الاتجاهات متصلة

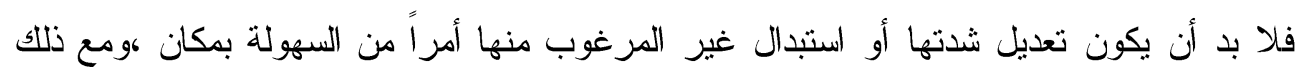
فإن الاتجاهات لا تتغير أو نستبدل بنفس السهولة التي تتعلم أو تكتسب بها لتها ، فالاتجاه بعد نشأنه

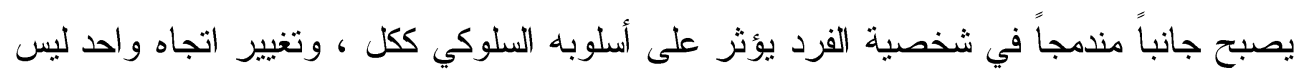

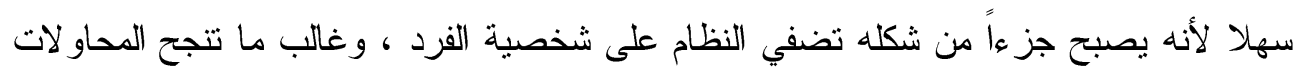

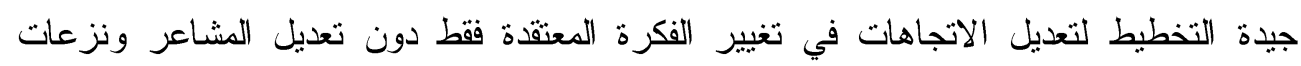

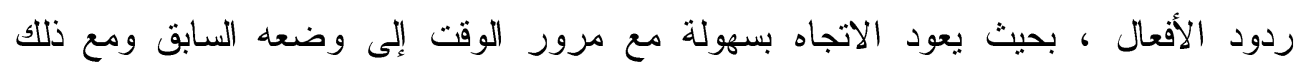

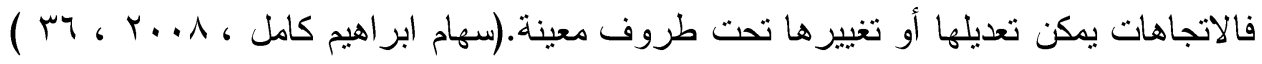


د / ريـهام رفعت محمد المليجي مدي

فاعلية برنامج وسائط متعدة لتمية ثقافة أطفال الروضة د/ رانيا محمد نبيل حسن الجندي رامي

ومن المعروف أن الاتجاهات النفسية يتم اكتسابها و تكونها عن طريق عمليات التعلم،

و إنها تتسم بالاستقرار و الدوام النسبي لكن ذلك لا يعني استحالة تغييرها أو تعديلها ؛ إذ يمكن

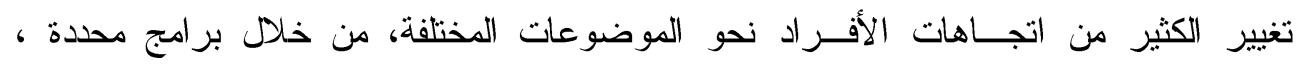
تستهدف تغييرات معينة في الاتجاه النفسي للفرد بصورة أو بأخرى · ( نزار حسين النفاخ، $(I r V-1 r q \cdot r \cdot N$

ولعل هذا الرأي الأخير قد أسهم في محاولة الباحثتين لاستخدام برنامج متعدد الوسائط في تعريف الأطفال ببعض المهن اليدوية و تعديل اتجاهاته نحوها . فروض البحث: : الفرض الأول " يوجد فرق دال إحصائيا بين متوسطي درجات أطفال عينــة البحــث فــي

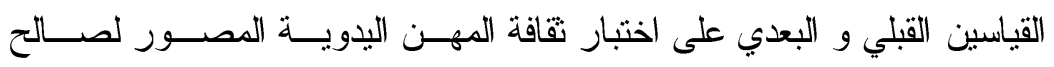

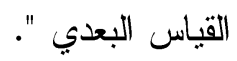

الفرض الثاني " يوجد فرق دال إحصائيا بين متوسطي درجات أطفال عينــة البحــث فــي القياسين القبلي و البعدي على مقياس الاتجاه نحو بعض المهن البدوية لصــالح القياس البعدي ". - n - n

الفرض الثالث " توجد فاعلية للبرنامج المقترح في تعريف الأطفال ببعض المهن اليدوية

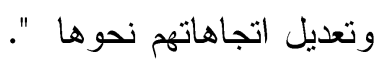

$$
\text { أدوات البحث: }
$$

\section{أولاً- برنامـج الوسائط المتعددة :}

تكون برنامج الوسائط المتعددة من عدة أنشطة كلها تذور حول المهن اليدوية و عددها ( r ا مهنة : الصياد والمزارع و الفران و بائع الخضار و الفاكهة و عامل المصنع و

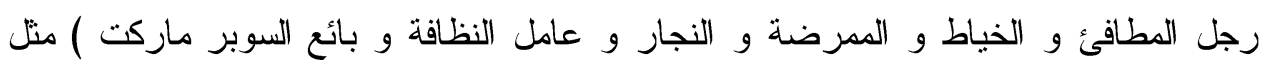
الألعاب و البطاقات المصورة و المجسمات و القصص الالكترونية و الكتب التفاعلية و الأناشيد و الرسم و التلوين والعاب البازل و كوتثينة المهن و لعب الأدوار و الرسوم الثابتة و المتحركة و كلها تدور حول تعريف الأطفال بالمهن و الأدوات الخاصة بها و مكان ممارستها و أهميتها في حياتتا و تعديل اتجاه الأطفال نحوها ، تم إعداد البرنامج وقةاً للمر احل التالية: 
1- مرحلة التصميم: وفيها نم وضع الخطوط العريضة لما ينبغي أن يحتويه البرنامج من

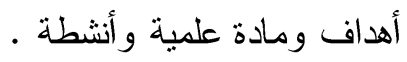

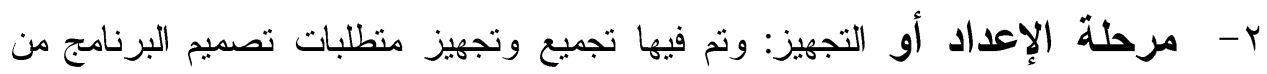

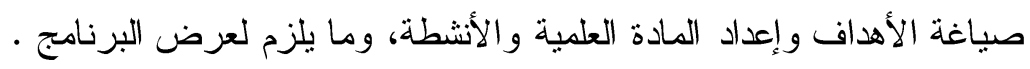

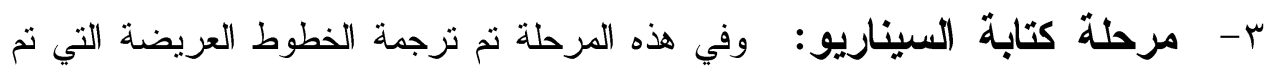

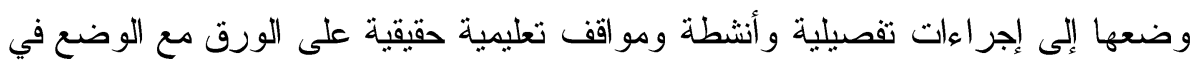
الاعتبار ما تم إعداده وتجهيزه بمرحلة الاعداد من منطلبات.

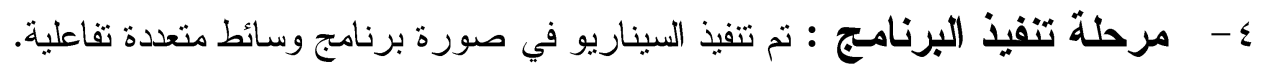

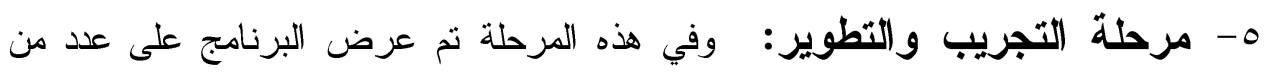
المحكمين في مجال تكنولوجيا צ- لتعليم ورياض الأطفال بهدف التحسين والتطوير، وفي ضوء هـ تعديلاتهم تم إخر اج البرنامج في صورته النهائية." وهدف البرنامسج بصفة عامة اللي تتمية نقافة أطفال الروضة حول بعض المهن اليدوية و تعديل اتجاهاتهم نحوها

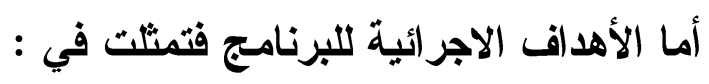
يكون الطقل في نهاية مروره بالبرنامج قادرا على ان :يتعرف على المهن الليدوية المختلفة.

يستمتع بسماع الأغاني عن المهن اليدوية من خلال الوسائط . يتعرف على الادوات الخاصة بكل مهنة يدوية. • يصنف الملابس الخاصة بكل مهنة يدوية. يميز بين المهن اليدوية المختلفة من خلال الصور والبطاقات . يفرق بين أدوات المهن اليدوية المختلفة. يذكر أهمية العمل اليدوي في حياتنا .

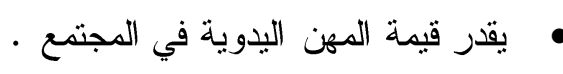

" ملحق (1) (1) 
د / ريـهام رفعت محمد المليجي مدي

فاعلية برنامج وسائط متعدة لتمية ثقافة أطفال الروضة د/ رانيا محمد نبيل حسن الجندي رامي

• برتب أجز اء الصورة الخاصة بكل مهنة يدوية على حده ترتيبا صحيحا .

• يتعرف على الأدوات المختلفة لكل مهنة .

• برسم شخصيات المهن اليدوية.

• يلون شخصيات وأدوات وملابس وأماكن المهن اليدوية.

• يعرف قيمة المهن اليدوية في حياتنا.

• يقلد شخصيات أصحاب المهن اليدوية من خلال مشاهدة القصص الاككترونية و الفيديو

ميكر .

• بطرح أسئلة عن المهن اليدوية .

يكون مجسما للأدوات المستخدمة في المهن اليدوية.

يوصل بين المهن وأدواتها وأماكن ممارستها في الكتب التفاعلية .

وقد استغرق تطبيق البرنامج ثلاث أسابيع بواقع خمسة أيام في الأسبوع و مدة النشاط

الواحد .7 دقيقة موزعة على جدول الأشطة اليومي للطفل و فيما يلي جدول زمني يوضح

الجدول الزمنى لأشطة البرنامج

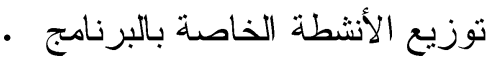

\begin{tabular}{|c|c|c|c|}
\hline التقويم & أسلوب التعلم & النشاط & 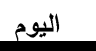 \\
\hline 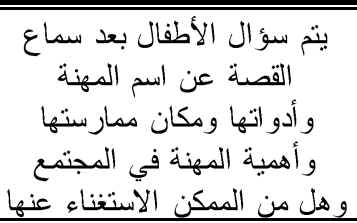 & 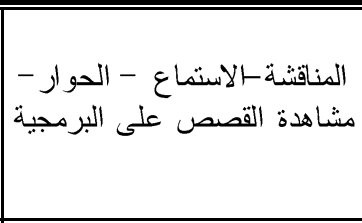 & القصص الاككترونية & الاول \\
\hline 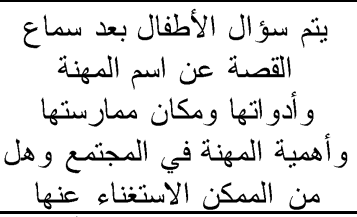 & مثناهدة القصص - الحو ار - الاستماع البرمجية & (استكمال النشاط السابق الاكثرونبة ) & التاني \\
\hline 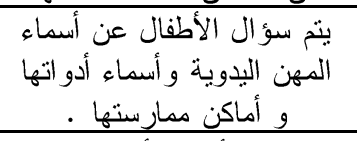 & عرض الرسوم على الاطفال & البطاقات و الصور و الرسوم & الثالث \\
\hline 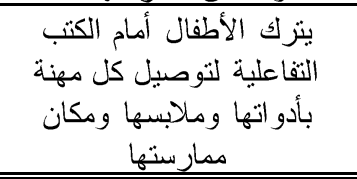 & 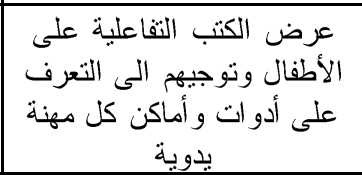 & الكتب التفاعلية & 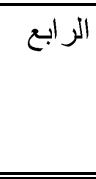 \\
\hline
\end{tabular}

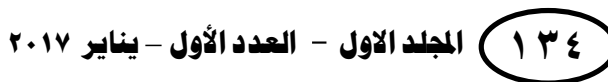




\section{المجلة العلمية لكلية رياض الاطفال - جامعة اسيوط}

\begin{tabular}{|c|c|c|c|}
\hline التقويم & أسلوب التعلم & النشاط & اليوم \\
\hline 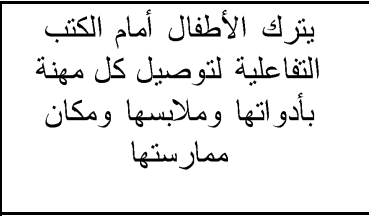 & 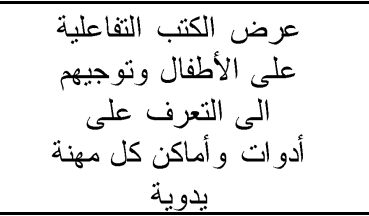 & (ابع النشاط النقاعلية ) & الخامس \\
\hline 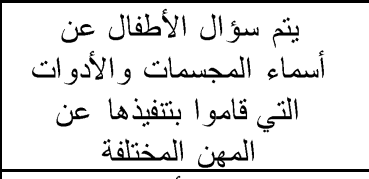 & 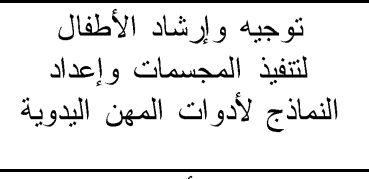 & كل مهنة المجسات و النماذج لأدو ات & السادس \\
\hline 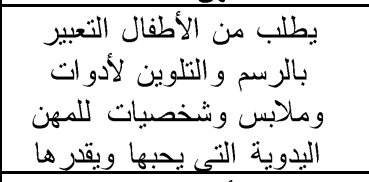 & 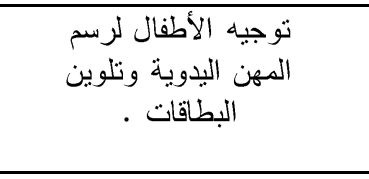 & التلوين و الرسم & السابع \\
\hline 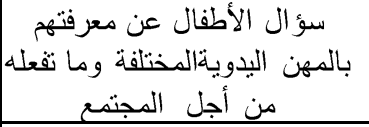 & مشاهدة الأطفال الفيديو ميكر & الفيديو مبكر & الثامن \\
\hline 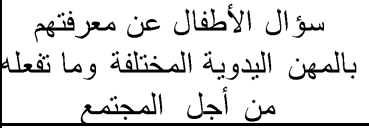 & صن خلال مشناهدة الكمبيونز ـ منحركة & 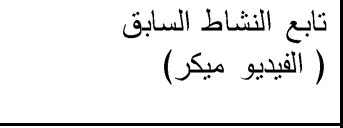 & التاسع \\
\hline 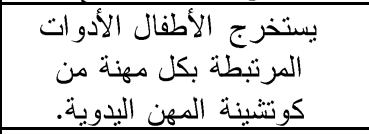 & 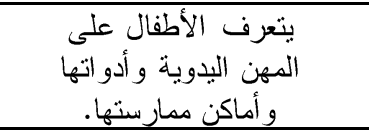 & كوتثنينة المهن & العاشر \\
\hline سؤ ال الأطفال عن مدى نقدير هم يدوية. & 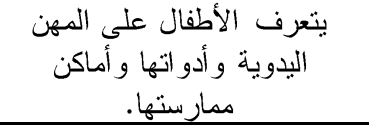 & 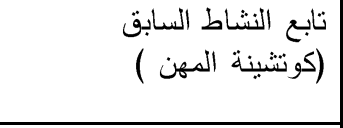 & عشر الحادى \\
\hline يتم سؤال الأطفال عن أسماء اليدوية وأهمية & 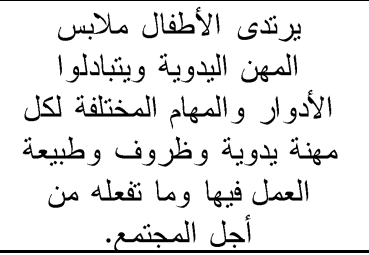 & لعب الادو ار & عشر الثنى \\
\hline يتم سؤال الأطفال عن المهن وهي هفيدة ام لا هيد & 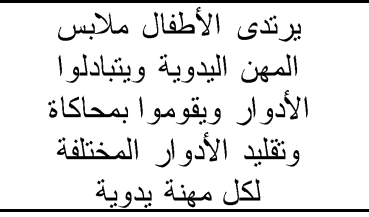 & 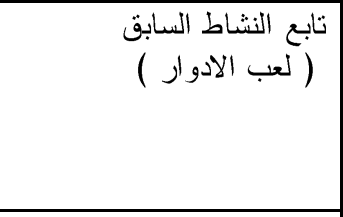 & عشر \\
\hline 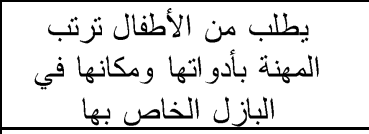 & 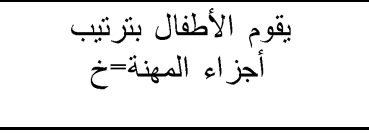 & ألعاب البازل & ع الر ابع \\
\hline ينتم سؤال الأطفال عن دور المهزية & 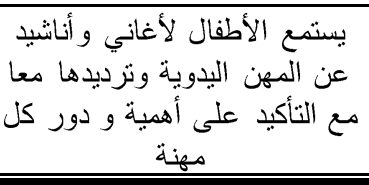 & 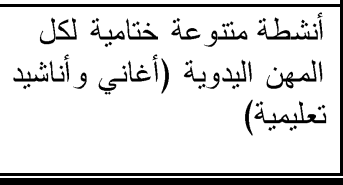 & عشر \\
\hline
\end{tabular}


د / ريـهام رفعت محمد المليجي مدي

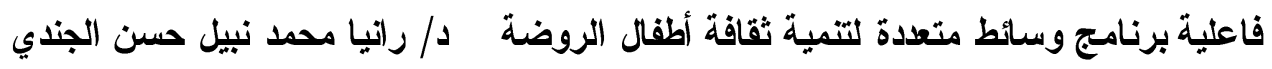

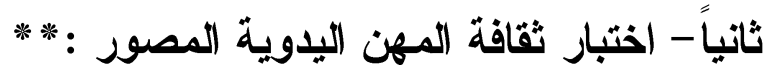

تم إعداد الاختبار بعد الاطلاع على الكتابات النظرية و الدراسات العربية والأجنبية و بعض المقاييس العربية والأجنبية المتعلقة برياض الأطفال .

وتحدد الهدف العام من الاختبار في تعرف مدى اكتساب الأطفال مجموعة البحث لبعض

المهن اليدوية ( T ) مهنه - و التي سبق ذكرها - و أدو اتها و أماكن مدارستها .

- كفاعة اختبار ثقافة المهن اليدوية المصور:

: Validity الصدق (1)

اعتمدت الباحثتان في حساب صدق اختبار ثقافة المهن اليدوية المصور على ما يلي :

\section{Logical Validity (الصدق المنطقي ( صدق المحكمين -}

تم عرض الصورة الأولية للاختبار على مجموعة من السادة المحكمين المتخصصين في مجال رياض الأطفال، و الذين كانت لهم دراسات أو أبحاث في هذا المجال بهدف: التأكد من مناسبة الفقرات للمفهوم المراد قياسه، وتحديد غموض بعض الفقرات لتعديلها، وحذف ولف بعض الفقرات غير المرتبطة بهذف الاختبار، أو غير مناسبه لطبيعة وخصائص أطفال الروضة . الرضة

وفي ضوء آر اء السادة المحكمين نم تعديل بعض فقرات الاختبار ، وحذف الفقرات التـي

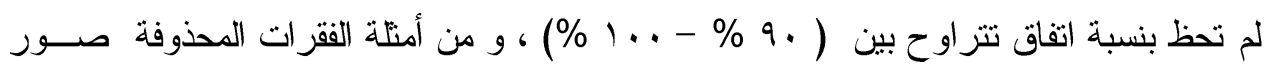

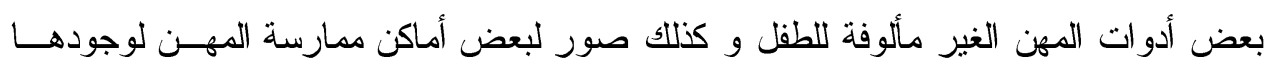

$$
\text { في دول اوروبية و أجنبية ( بعيدة عن المجتمع العربي ) . }
$$

وقد انتتمل الاختبار في صورته الأولية على •ب فقرة منها ( . ) فقرات تقيس المهن و أدواتها و ( ( ) فقرات أخرى تقيس المهن و أماكن ممارستها، وتم تطبيق المقياس على العينة الاستطلاعية للاستقرار على الصورة النهائية له.

وقد بلغت درجة الاختبار الكلية . r درجة و تم تطبيق الاختبار بطريقة فردية مع كل

$$
\text { طفل على حدة. }
$$

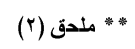


- الصدق التمييزي: -

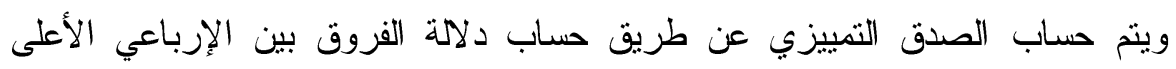

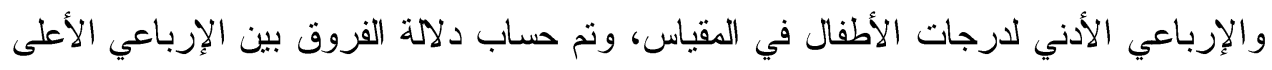

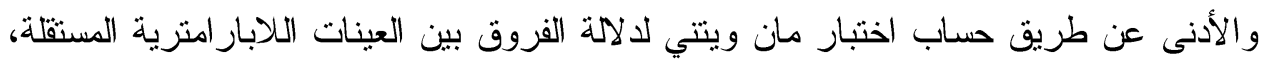
وجدول (1) و يوضح نلك.

جدول(1)

متوسط ومجموع الرتب وقيمة Z ومستوى الدلالة

\begin{tabular}{|c|c|c|c|c|c|}
\hline الالامة & قيمة Z & مجموع الرثب & متوسط الرتب & العدد & المجموعة \\
\hline \multirow{2}{*}{ دال عند +.. } & \multirow{2}{*}{ r.乏) } & †^... & $\varepsilon \ldots$ & V & دنيا \\
\hline & & VV... & $11 \ldots$ & $V$ & علبا \\
\hline
\end{tabular}

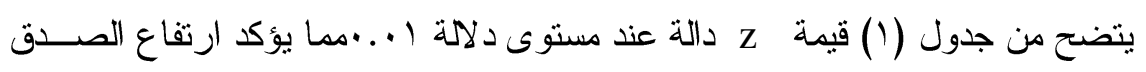

$$
\text { التمييزي لاختبار التعرف على المهن اليدوية. }
$$

:Reliability الثبات (Y)

\section{- Alpha Cronbach Method طريقة ألفا كرونباكs -}

استخدمت الباحثتان معادلة ألفا كرونباك وهي معادلة نستخدم لإيضـــاح المنطــق العــام

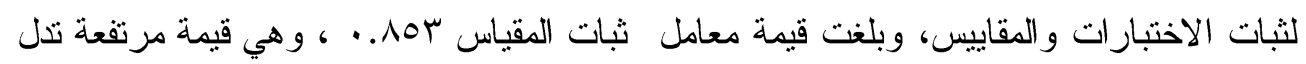

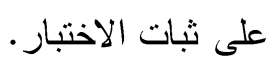
- التجزئة النصفية لفقز ات الاخترن

وللتأكد من ثبات الاختبار نم تجزئة فقراته إلى أسئلة فردية وأخرى زوجية ثـــ حســاب

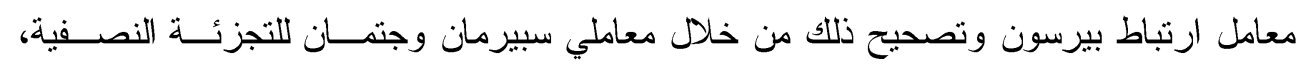
ويوضح جدول (ع) معاملات الارنباط . 
د / ريـهام رفعت محمد المليجي مدي

فاعلية برنامج وسائط متعدة لتمية ثقافة أطفال الروضة د/ رانيا محمد نبيل حسن الجندي رامي

جدول (r)

معاملات التجزئة النصفية لمقياس التعرف على المهن اليدوية

\begin{tabular}{|c|c|c|c|}
\hline الدلالة & معامل جتمان & معامل سبيرمان & الخو اص \\
\hline$\ldots 1$ & .941 &. $.94 \wedge$ & الكقياس \\
\hline
\end{tabular}

يتضح من جدول (Y) أن معاملات الارنباطدالة عند مستوى (...، وذللك يؤكد

ثبات المقياس.

*ثالثًاً- مقياس اتجاه الطفل نحو بعض المهن اليدوية :

تم إعداد الدقياس بعد الاطلاع على بعض الكتابات النظرية والدراسات العربية

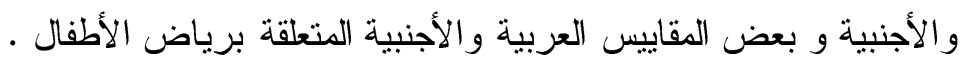

وتحدد الهدف العام من المقياس في تعرف اتجاهات الأطفال مجموعة البحث نحو

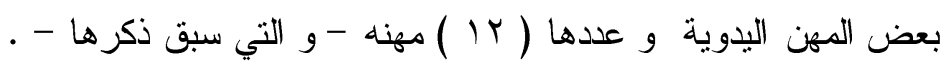

وتم بناء فقرات المقياس الأولية ثم تم عرض الاختبار على مجموعة من الأساتذة

المتخصصين في مجال رياض الأطفال للتأكد من مدى سلامة الصياغة اللغوية للعبارات

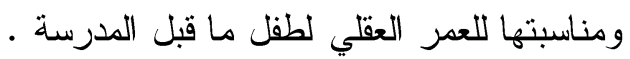

وبعد إجراء التعديلات التي أثداروا إليها، تمت صياغة عبارات المقياس بحيث تضمن

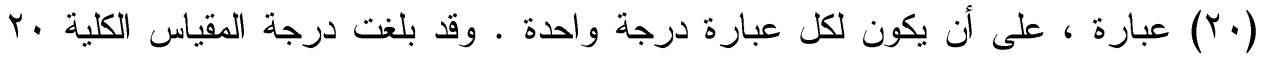

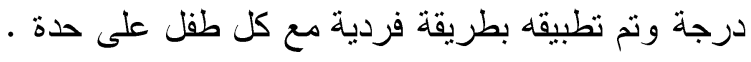

كفاءة مقياس اتجاهات أطفال الروضة نحو بعض المهن اليدوية :

: Validity (1) (الصدق )

اعتمدت الباحثتان في حساب صدق المقياس على ما يلي :

ملحق (T)

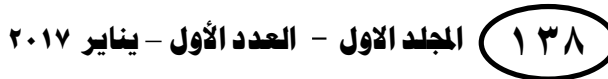




\section{Logical Validity الصدق المنطقي ( صدق المحكمين )}

تم عرض الصورة الأولية للمقياس على مجموعة من السادة المحكمين المتخصصين

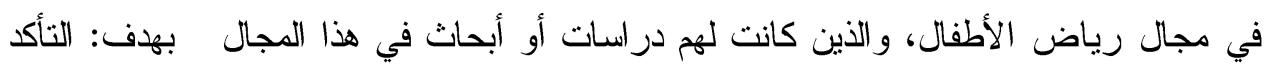

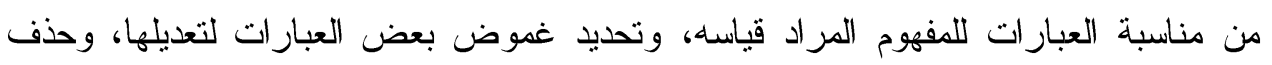
بعض العبارات غير المرتبطة بهدف الاختبار، أو غير مناسبه لطبيعة وخصائص أطفال الروضة .

وفي ضوء آراء السادة المحكمين تم تعديل عبارات المقياس ، وحذف بعضها ؛ و التي

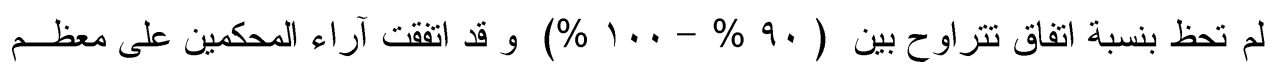

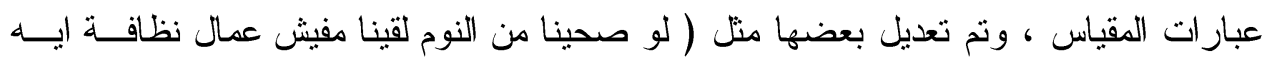

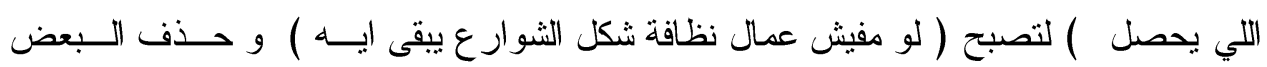
الأخرى منل ( هل من المكن الطبيب ينجح في عمله بدون الممرضة ) ) و ( ايه الارتباط بــين

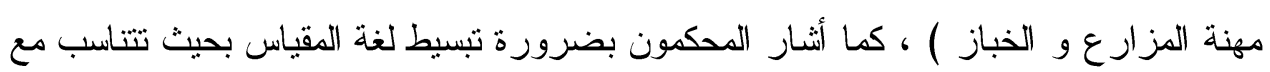

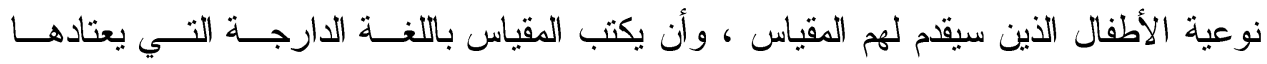
الأطفال.

وقد الثتمل الدقياس في صورته الأولية على ·r فقرة ، وتم تطبيقه على العينة الاستطلاعية للاستقرار على الصورة النهائية له. بلغت درجة المقياس الكلية • ب درجة كما تم تطبيق الاختبار بطريقة فردية مع كل طفل على حدة. - الصدق التمبيزي: تم حساب الصدق التمييزي عن طريق حساب دلالة الفروق بين الإرباعي الأعلى

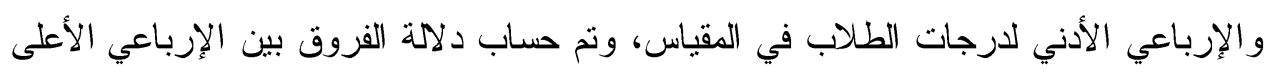

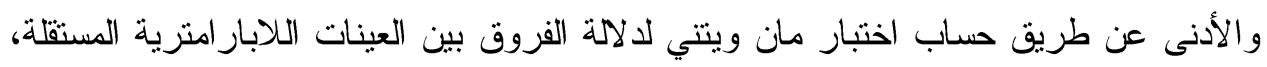
وجدول (ץ) يوضح نلك. 
د د ر ريهام رفعت محمد المليجي

فاعلية برنامج وسائط متعددة لتنمية ثقافة أطفال الروضة د/ رانيا محمد نبيل حسن الجندي رفي معي

جدول(r)

متوسط ومجموع الرتب وقيمة Z ومستوى الالالة

\begin{tabular}{|c|c|c|c|c|c|}
\hline الدلالة & قيمة Z & مجموع الرتب & متوسط الرتب & العدد & المجموعة \\
\hline \multirow{2}{*}{ دال عند ا +... } & \multirow{2}{*}{ r. $\leqslant 0$} & ro... & $0 .$. & v & دنيا \\
\hline & & $\Lambda \varepsilon_{\ldots} .$. & ir... & v & عليا \\
\hline
\end{tabular}

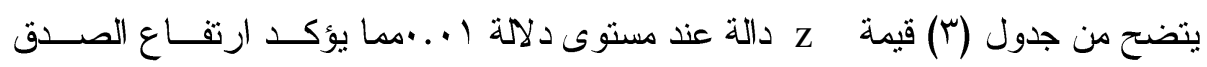
التمييزي لكقياس اتجاه الاطفال نحو بعض المهن اليدوية.

:Reliability الثبات

- Alpha Cronbach Method طريقة ألفا كرونباك -

استخدمت الباحثنان معادلة ألفا كرونباك وهي معادلة نستخدم لإيضاح المنطق العام لثبــات

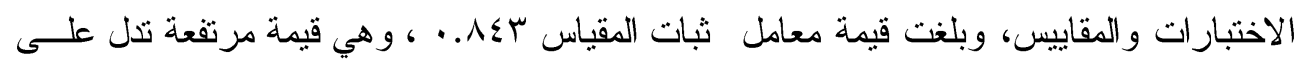
ثبات المقياس. - التجزئة النصفية لفقرات المقياس:

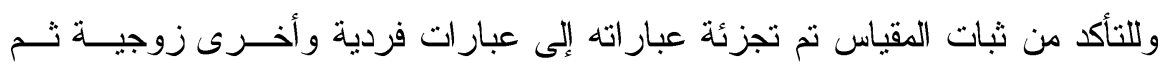

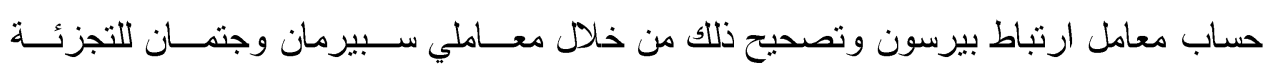

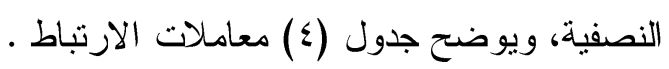

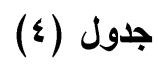

معاملات التجزئة النصفية لمقياس الاتجاه نحو بعض المهن اليدوية

\begin{tabular}{|c|c|c|c|}
\hline اللالة & معامل جتمان & معامل سبيرمان & الخو اص \\
\hline$\ldots 1$ & .947 & .941 & المقياس \\
\hline
\end{tabular}

يتضح من جدول (乏) أن معاملات الارنباطدالة عند مستوى (....، وذلك يؤكد ثبات 


\section{تجربة البحث:}

تم اتباع الإجراءات التالية لتطبيق تجربة البحث:

اختيار مجموعة البحث واثتملت على (·ץ) طفلاً وطفلة بالمستوى الثاني

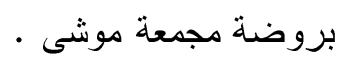

- النطبيق القبلي لاختبار نقافة الطفل نحو بعض المهن الليدوية ، ومقياس اتجاه

الاطفال نحو بعض المهن اليدوية على مجموعة البحث.

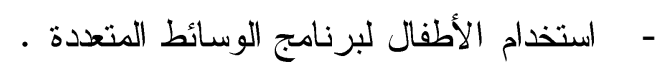

- النطبيق البعدي لاختبار نقافة الطفل نحو بعض الطب المهن الليدوية ، ومقياس اتجاه

الاطفال نحو بعض المهن اليدوية على مجموعة البحث.

$$
\text { نتائج البحث: - رصد الدرجات ومعالجتها إحصائياً. }
$$

سوف يتم عرض النتائج من خلا فروض البحث التالية:

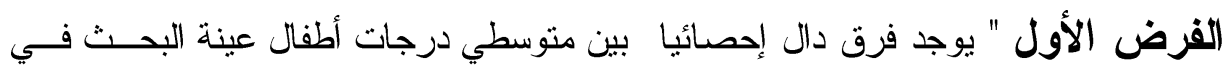

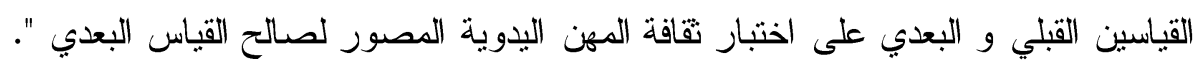

للتحقق من صحة هذا الفرض استخدمت الباحثتان اختبار ت للعينات البار امترية للأزواج

المرتبطة من خلال البرنامج الاحصائي Spss وجدول (0) يوضح ذلتك.

جدول) (0)

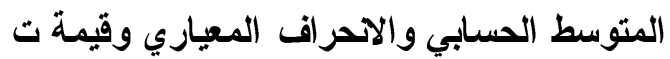

ومستوى الدلالة للفروق بين متوسطي درجات الأطفال قبل وبعد تطبيق الختبار ثقافة المهن

\begin{tabular}{|c|c|c|c|c|c|c|}
\hline مستوى & قيمة ت & الالحعراف & الحسابي & العدد & التطبيق & المقياس \\
\hline \multirow{2}{*}{ دال عند } & \multirow{2}{*}{ r...II } & T.T. Q & S.АTTV & $r$. & قبلي & \multirow{2}{*}{ الدرجة الكلية } \\
\hline & & 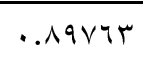 & $19.074 \mathrm{~V}$ & $r$. & بعدي & \\
\hline
\end{tabular}
اليدوية المصور الاططفر

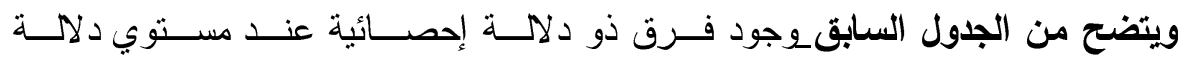

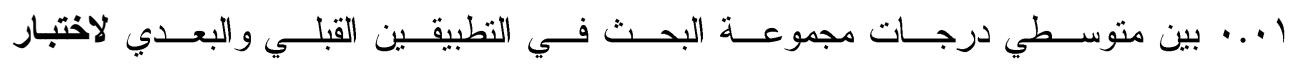


د / ريـهام رفعت محمد المليجي مدي

فاعلية برنامج وسائط متعدة لتمية ثقافة أطفال الروضة د/ راتيا محمد نبيل حسن الجندي

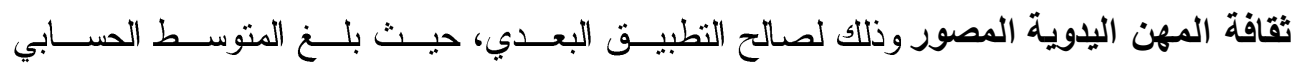

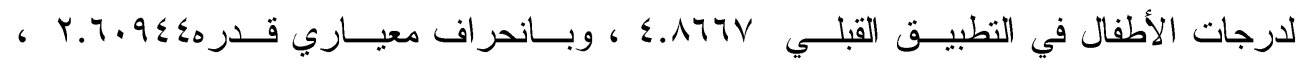

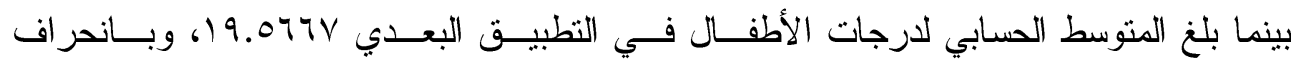

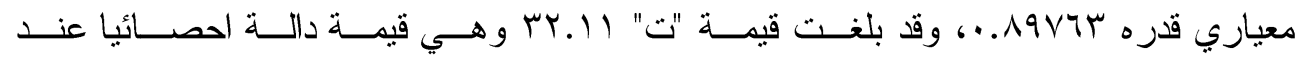

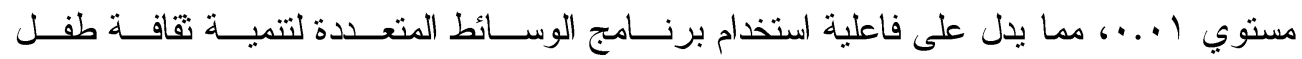

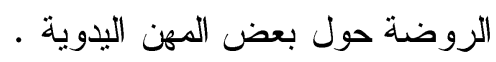

ويوضتح الثكل التالي متوسطات درجــات مجموعــة البحــث فـي التطبيةـين القبالـي

والبعدي لاختبار ثقافة بعض المهن اليدوية المصور :

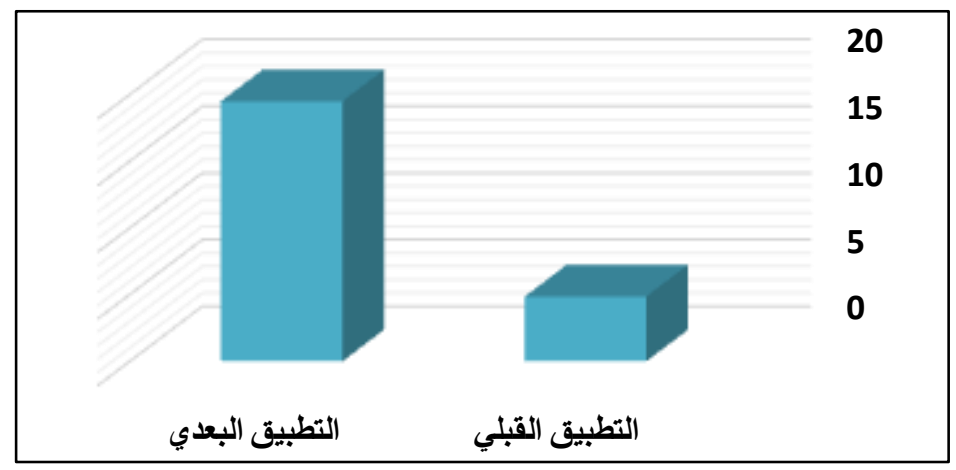

شكل (1) (1)

متوسطات درجات مجموعة البحث في التطبيقين القبلي والبعي لاختبار ثقافة المهن

اليدوية المصور

• وبذلك تكون الباحثنان قد أجابتا عن السؤال الفرعي الثالث و الذي نصه :

ما فاعلية البرنامج متعدد الوسائط لتنمية ثقافة طفل الروضة نحو بعض المهن اليدوية ؟

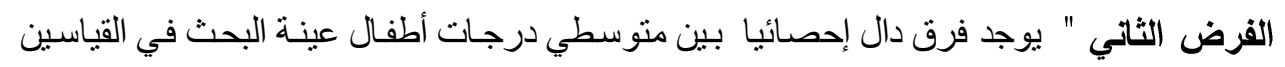
القبلي و البعدي على مقياس الاتجاه نحو بعض المهن اليدوية لصالح القياس البعدي ".

للتأكد من صحة الفرض الثاني تم تطبيق مقياس اتجاهات أطفال الروضة حول بعض المهن الياوية على مجموعة البحث ونلك قبل وبعد استخدام برنامج الوسائط المتعددة ، وتم استخدام اختبار ت للعينات البار امنرية للازواج المرنبطة من خلال البرنامج الاحصائي Spss وجدول (†) يوضح ذلك. 


\section{جدول) (7)}

المتوسط الحسابي والاحمراف المعياري وقيمة ت ومستوى الالالة للفروق بين متوسط درجات الأطفال قبل ويعد تطبيق مقياس الاتجاه

\begin{tabular}{|c|c|c|c|c|c|c|}
\hline مستوى الالامة & قيمة & الالنحر اف المعياري & المتوسط الحسابي & العدد & التطبيق & المقياس \\
\hline \multirow{2}{*}{ دال عند } & \multirow[t]{2}{*}{ Or.9T } & I.V.人TV & Y.747V & r. & قبلي & \multirow{2}{*}{ الدرجة الكلبة } \\
\hline & & . VYVqT & $19.077 \mathrm{~V}$ & r. & بعدي & \\
\hline
\end{tabular}

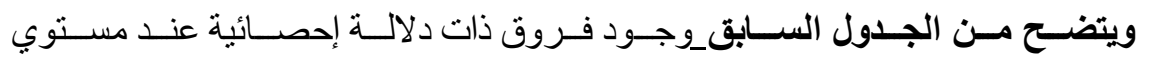

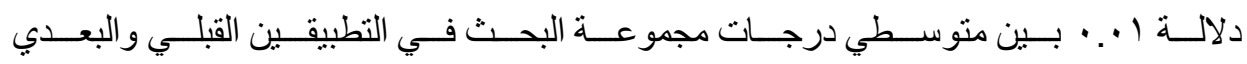

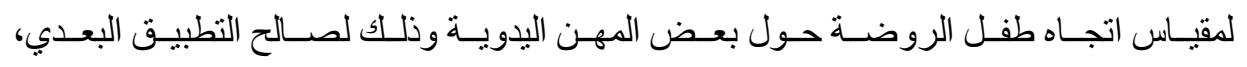

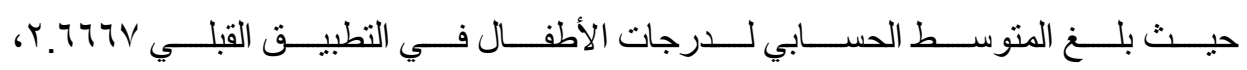

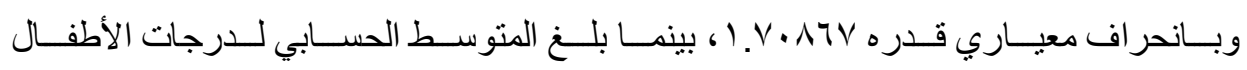

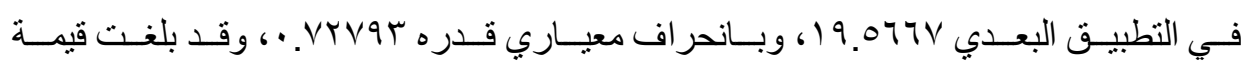

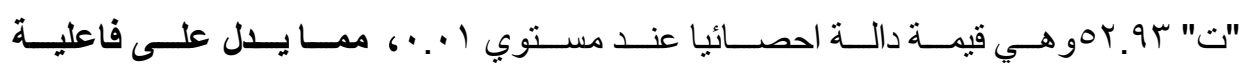

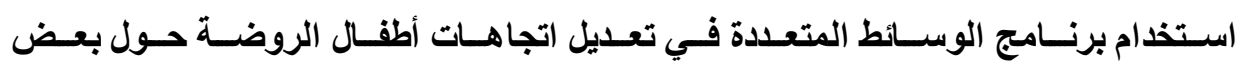

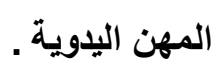


د / ريـهام رفعت محمد المليجي مدي

فاعلية برنامج وسائط متعدة لتمية ثقافة أطفال الروضة د/ راتيا محمد نبيل حسن الجندي

ويوضح الثــكل التــالي متوســطات درجــات مجموعــة البحــث فــي التطبيةـين

القبلي و البعدي لمقياس اتجاهات أطفال الروضة حول بعض المهن اليدوية:

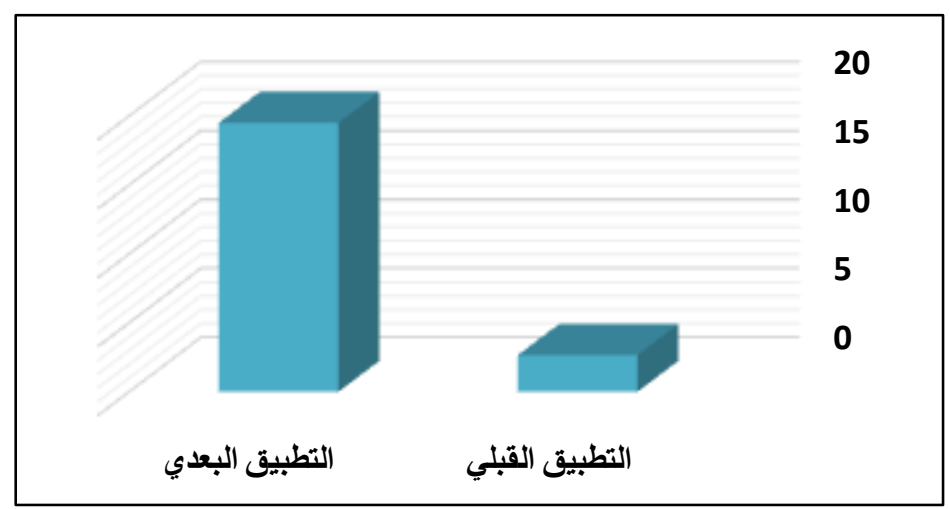

شكل (r)

متوسطا درجات مجموعة البحث في التطبيقين القبلي والبعدي لمقياس اتجاهات أطفال

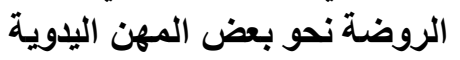

وبذلك تكون الباحثتان قد اجابتا عن السؤال الفرعي الر ابع ما فاعلية البرنامج متعدد

الوسائط لتعديل اتجاهات أطفال الروضة نحو بعض المهن اليدوية ؟

الفرض الثالث " توجد فاعلية للبرنامج المقترح في تعريف الأطفال ببعض المهن اليدوية وتعديل اتجاهاتهم نحوها ".

للتحقق من صحة هذا الفرض استخدمت الباحثتان معادلة مربع إيتا لقياس حجــم الأثــر ومعدل الكسب المعدل لبلاكك للتأكد من فاعلية البرنامج المقترح من خلال البرنامج الاحصــائي Spss

ويوضح جدول (V) قيم ت و مربع ايتا و معدل بلاك و الالالات الاحصائية . 
المجلة العلمية لكلية رياض الاطفال - جامعة اسيوط

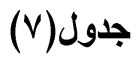

المتوسط الحسابي والاحر اف المعياري وقيمة ت وحجم الأثر ومعدل بلاكك لأدوات البحث

\begin{tabular}{|c|c|c|c|c|c|c|c|c|}
\hline الالاة & معدل & مربع & قيمة t & الالنعر اف & المتوسط & العدد & التطبيق & المقياس \\
\hline \multirow{2}{*}{ كبير } & \multirow{2}{*}{1.21} & \multirow{2}{*}{$.9 V$} & \multirow{2}{*}{ r..।I } & $r .7 .9 \leq \varepsilon$ & E.ATTV & r. & قبلي & \multirow[t]{2}{*}{ التعرف } \\
\hline & & & & חד & $19.077 \mathrm{~V}$ & r. & بعدي & \\
\hline \multirow{2}{*}{ كبير } & \multirow{2}{*}{$1 . \wedge r$} & \multirow{2}{*}{. .99} & \multirow{2}{*}{ or.9r } & $1 . v \cdot \Lambda T V$ & r.TTTV & r. & قبلي & \multirow[t]{2}{*}{ الاتجاه } \\
\hline & & & & . .VYVqr & $19.074 \mathrm{~V}$ & r. & بعدي & \\
\hline
\end{tabular}

$$
\text { يتضح من جدول (V) ما يلي: }
$$

- قيمة حجم الأثر كبيرة لكل من اختبار تقافة المهن اليدوية المصور و مقياس الاتجــاه نحو المهن اليدوية، وذلك يؤكد استمر ارية البرنامج في تأثيره على الأطفال. - - معدل بلاكك لكل من ثقافة المهن اليدوية المصور و مقياس الاتجاه نحو المهن اليدوية

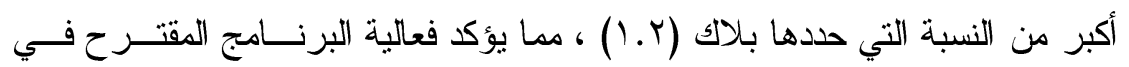
تعرف الأطفال وتتمية الاتجاه نحو بعض المهند لئن اليدوية. 
د / ريـهام رفعت محمد المليجي مدي

فاعلية برنامج وسائط متعدة لتمية ثقافة أطفال الروضة د/ راتيا محمد نبيل حسن الجندي

تفسير النتائجج:

ترجع الباحثتان ما أظهرته نتائج البحث الحالي من أثر واضتح لاستخدام البرنامج المتعدد

الوسائط للأسباب التالية:

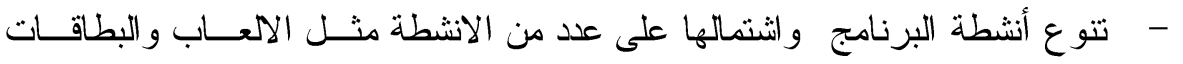
المصورة و المجسمات و القصص الاككترونية والكتب التفاعلية و الأناشيد و الرســ

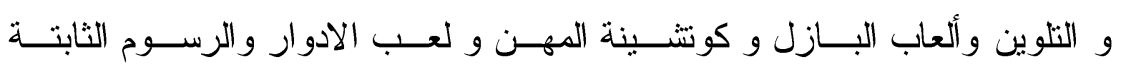
و المتحركة.

- - بناء البرنامج على أسس علمية صحيحة ، و اتباع المر احل المتتاليــة لبنائــهـ بثـــل محكم.

- - تو افر الوقت و الامكانات لتنفيذ البرنامج والجهر الضخم لتجهيزه وتنفيذه. - - تعاون إدارة روضة مجمعة موشا بإدارة أسيوط التعليمية في توفير متطلبات تطبيـق البحث ومساعدة معلمات الروضة للباحثثين في تتفيذ تجربة البحث. - - دافعية الأطفال عند تنفيذ التجربة، لما اثتتمل عليه البرنــامج مــن صــور ورسـوم وحركة، مما أدى إلى تتمية نقافة المهن و تعديل الاتجاهات نحوها .

(التوصباث:

في ضوء نتانج البحث توصي الباحثتان بما يلي:

- زيادة وعي معلمات رياض الأطفال بتعريف اطفال الروضة ببعض المهن و الحرف

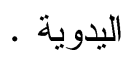

r- عمل برامج تدريبية لمعلمات الروضة على طرق إكساب الأطفال المعرفة حول المهن المختلفة و تحسين اتجاهاتهم نحوها . المعاه س- إضافة وحدة عن المهن و الحرف اليدوية ضمن منهج رياض الأطفال ( حقي ألعب و أتعلم و أبتكر ) 


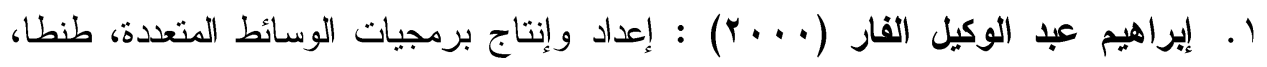
الدلتا لتكنولوجيا الحاسبات ،ص و IV

r . أحمد السناني ( rاع ا هـ ) : المنزلة الاجتماعية للمهن في المجتمع السعودي ، دراسة ميدانية مقارنة ، بحث غير منشور ، ص • . . .

r. أحمد محمد علم الاين وجلل علي سلام (ه . . r) : دراسة واقع الوسائط المطبوعة و الإككترونية و المتعددة، القاهرة، المؤتمر السنوي الأول للميديا

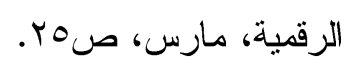

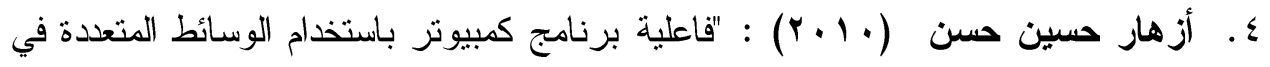

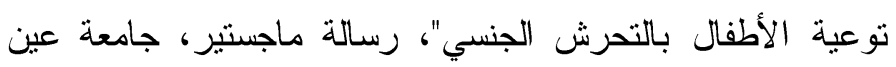

$$
\text { شمس، معهد الدراسات العليا للطفولة. }
$$

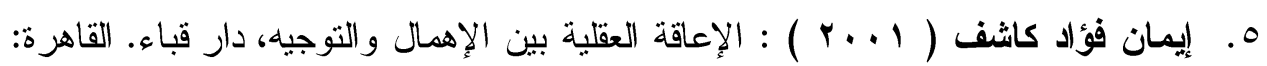

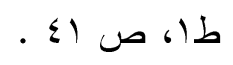

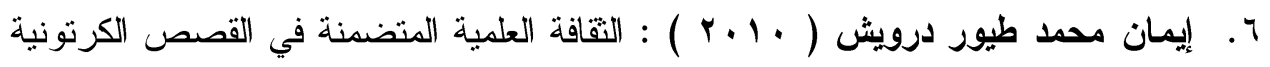
لطفل الروضة ، دراسة تحليلية نقدية ، رسالة ماجستير ، كلية

\section{· التربية ، جامعة طنطا}

V. باوى قنديل ، رمضان مسعد متولى (V . . r) : بينات تعلم الطفل الطبعة الأولى ، ط )

$$
\text { عمان - الاردن : دار الفكر. }
$$

^. حمد عبد الله الحميدان ( ^ . . r ) : دور البرامج التعليمية للتربية الفنية في التعريف بالحرف الثعبية ، رسالة ماجستير ، كلية التربية ، جامعة

$$
\text { • الملك سعود . بالجرق }
$$

9. ر راضي محمد الكبسي ( . . . . : اتجاهات الابناء نحو ابائهم المعوقين ، عمان ، دار

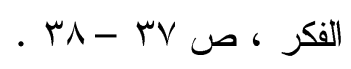

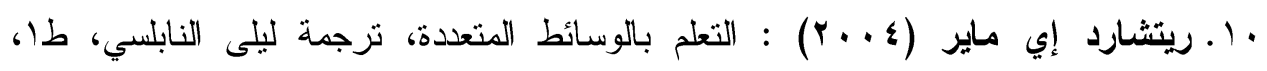

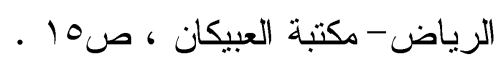


د / ريـهام رفعت محمد المليجي مدي

فاعلية برنامج وسائط متعدة لتمية ثقافة أطفال الروضة د/ راتيا محمد نبيل حسن الجندي

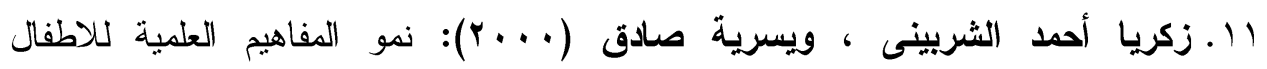
برنامج مقترح وتجارب لطفل ما قبل المدرسة ، القاهرة ، دار

$$
\text { الفكر العربى. }
$$

r ا ـ سامية يوسف صالح ( • . . r ) : دور الأسرة في التنمية التقافية لطفل الروضة ، مجلة

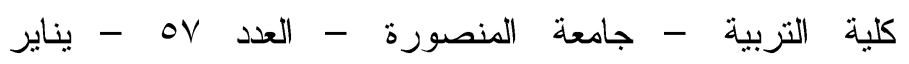

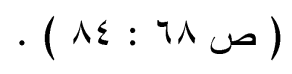

با . سعيد فالع السريحة ( r ع I ) : الصيت الاجتماعي للأعمال و أسس الاختيار المهني العوامل المؤدية على عزوف الثباب السعودي عن الأعمال الحرفية البسيطة ، رسالة ماجستير ، جامعة الملك عبد العزيز

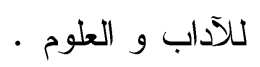

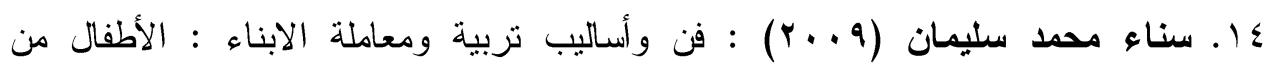

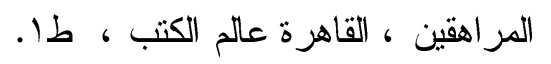

1 ـ سهام ابراهيم كامل ( ^ . . r ) : اتجاهات معلمات رياض الأطفال نحو العمل مع الطفل في ضوء بعض المتغيرات النفسية و الديموجرافية ، رسالة ماجستير ، قسم العلوم النفسية ، كلية رياض الاطفال ، جامعة

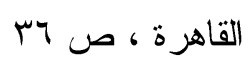

ا . سهير عثمان ديدان (11 (Y) : تصميم وفاعلية برنامج لتعديل اتجاهات الأطفال العاديين نحو المعاقين ذهنيا في المدارس الابتدائية بجدة ، المملكة العربية السعودية ، جامعة أم درمان ، رسالة دكتوراه

$$
\text { ( }(1, q-1)
$$

V ا ـ صلاح الاين محمود علام ( 0 . . ) ) : الأساليب الاحصائية الاستدلالية في تحليل بيانات

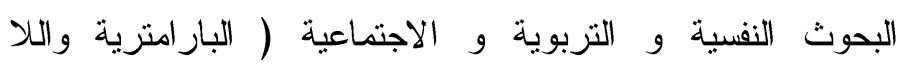

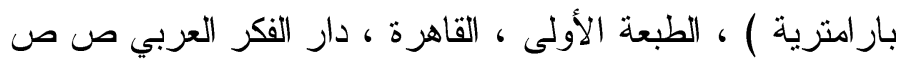

$$
r \cdot \Lambda-r \cdot V
$$

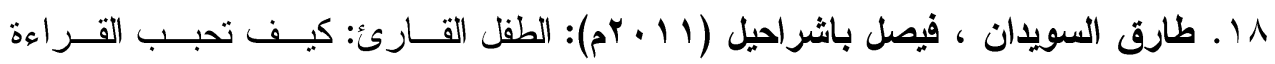
للأطفال الكويت شركة الابداع الفكري ، طساسر.

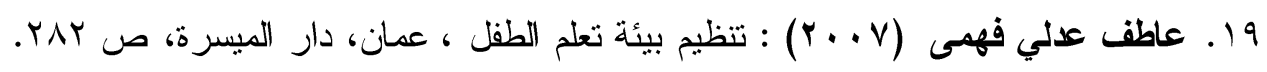

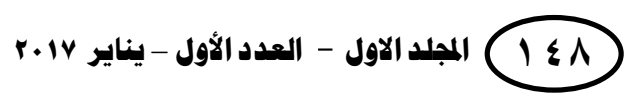


• . . عبد الرحمن محمد عسيري ( . . . . ) : الطموحات المهنية لدى أطفال المناطق الريفية والحضرية في المجتمع السعودي ، الكويت ، مجلة العلوم

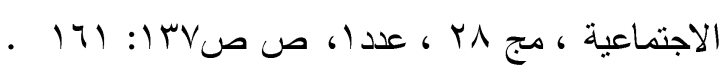

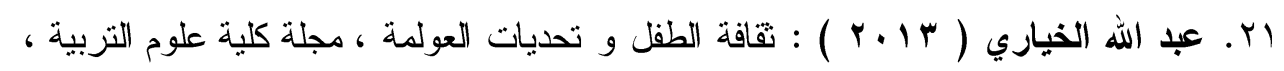

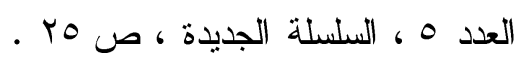

r . علي محي الدين راثد ( r r r) : أطفالك نجوم المستقبل ، الناشرون المتحدون ، ط r

بr . الغريب زاهر إسماعيل (1 . . r): تكنولوجيا المعلومات وتحديث التعليم، القاهرة، عالم

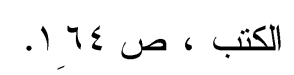

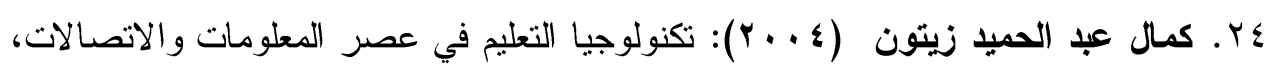

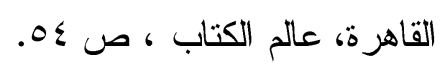

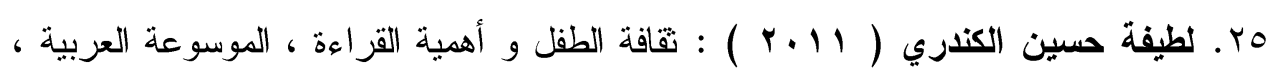

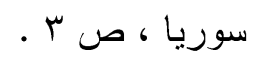

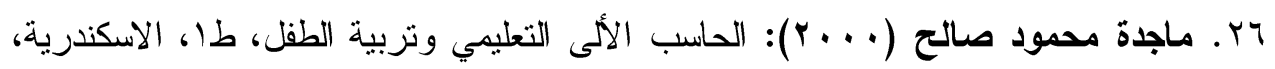

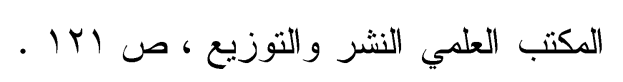

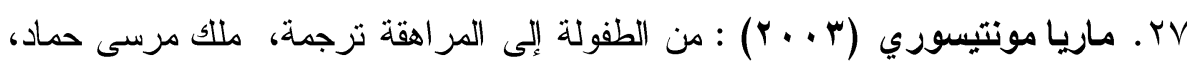

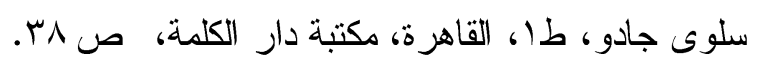

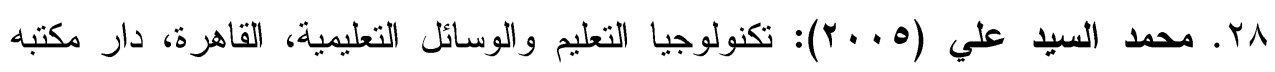

$$
\text { الإسراء للطبع ص r r. r. }
$$

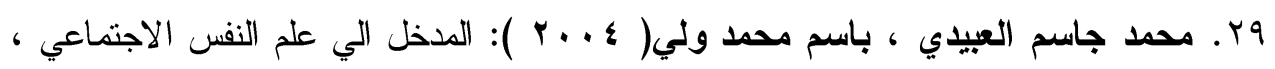

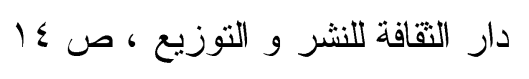

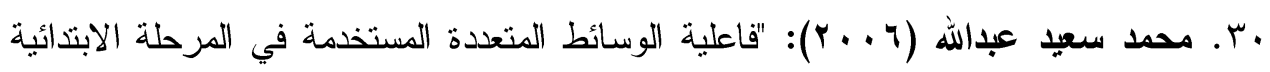
على التحصيل وتتمية مهارات اللغة الإنجليزية"، رسالة ماجستير

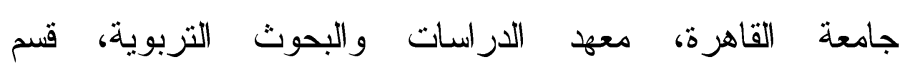

$$
\text { تكنولوجيا التعليم. }
$$

اب. محمد شفيق ( ^ . . ץ): علم نفس الاجتماعي ، المكتب الجامعي الحديث ، الاسكندرية،

$$
\text { (1) ص ( ) }
$$


د / د ريهام رفعت محمد المليجي

فاعلية برنامج وسائط متعدة لتمية ثقافة أطفال الروضة د/ راتيا محمد نبيل حسن الجندي

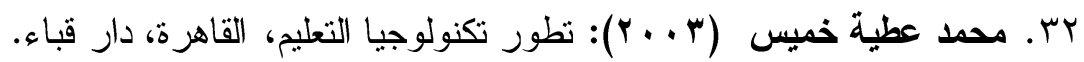

سب. محمد محمود الحيلة ، توفيق احمد مرعي (r . . . ) : المناهج التربوية الحديثة : مناهجها و عناصرها و اسسها و عملياتها ، ط س ، دار المسيرة

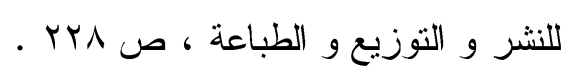

عس. مراد شلباية وآخرون (r (.r): تطبيقات الوسائط المتعدد، طا عمان، دار الكتب

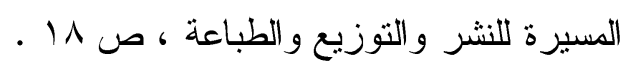

هr. موسى بلبول ( q . . r ) : اتجاهات بعض الانماط الجسمية نحو ادراك الذات البدنية في حصة التربية البدنية و الرياضية ، رسالة ماجستير ، كلية العلوم

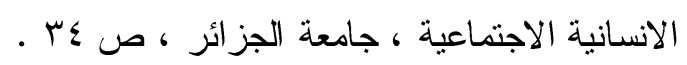

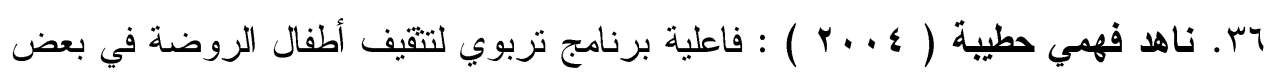
الممارسات الحياتية و تتمية اتجاهاتهم نحوها ، در اسات في المناهج

و طرق التذريس ، مصر ، عدد 91 ، ، اكتوبر ، ص

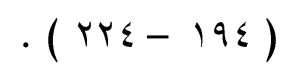

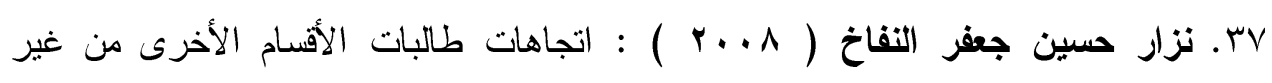
الاختصاص نحو التربية الرياضية ، مجلة علوم التربية الرياضية ، الرجية البية

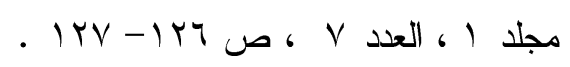

يץ. يوسف قطامي، و نايفة قطامي (1 . . r ) : سيكولوجية التذريس ، دار الثروق للنشر و

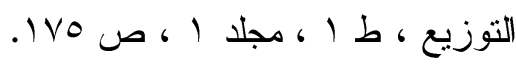

39. Alexander, S (2003): Multimedia for Learning Development, Application and Evaluation ", Australian Journal of Educational Technology, (vol.19, No 3,), P121-147.

40. Apostolos, S. \& Panagiotis, A.( 2005): "Effects of multimedia computer-assisted instruction (MCAI) on academic achievement in physical education of Greek primary students" Interactive Educational Multimedia, Volume 10. April .PP.61-77.

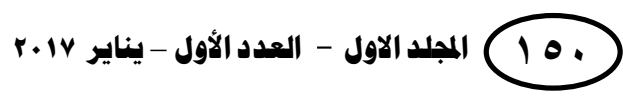




\section{المجلة العلمية لكلية رياض الاطفال - جامعة اسيوط}

41. Bohner, G., \& Wänke, M. (2002): Attitudes and attitudechange. Hove, UK: Psychology Press PP:20

42. Brock, T. and Green M. (2005): Persuasion: Psychological Insights and Perspectives, Thousand Oaks: CA: Sage Publications.

43. Comors,F.,Comors,P.,\& Meyer,C.A.(2016): What Makes A Multimedi Effective * Educational Leadership.

44. Fred. T. Hofstetter (2006): Enhancing Multiple intelligence Through Multimedia,(online), available at. http.//www.mhne.com/cit/hofstetter.

45. Kimball,J. W.,Kinney, E. M., Taylor, B. A., \& Stromer, R.(2013): Multimedia For Children With Autism: A Promising Package For Teaching Social Skills . Education and Treatment of Children, 27,280-298.

46. Meckes, S. (2004) :The Effect of Using The Computer as A Learning Tool in a Kindergarten Curriculum .PhD،Salve Regina University,DAI-65/04,p.1237.

47. Miller, K.( 2011 ): Preschool Activities for Thunderstorms ,How Contributor:/updated May 31 .

48. Natarajan, M.(2012): Multimedia and Data Transfer Technology:

The Challenges and Delivery. Desidoc Bulletin of Information Technology .23(4),1926.

49. Ivashkevich. (2009): Children's Drawing as a Sociocultural Practice:

Remaking Gender and Popular Culture. Studies in Art Education, 51(1), 50+. Retrieved March 4

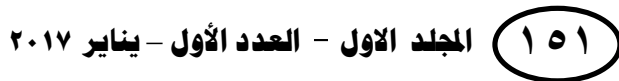


د / ريهام رفعت محمد المليجي

فاعلية برنامج وسائط متعدة لتمية ثقافة أطفال الروضة د/ رانيا محمد نبيل حسن الجندي رامي

50. Stephen plow Man,(2003):" From the Teacher's Perspective A Way

of Simplicity for Multimedia Design", Asia-pacific

Forum on Science Learning and Teaching, (Vol 10,

m1 Article 13), P 149,p 199.

51. O'Keefe, D. (2002): Persuasion: Theory and Research, Second Edition, Thousand Oaks: CA: Sage Publications Inc

52. Shirley A. Mecke (2004): Attention Guiding in Multimedia Learning " Learning and Instruction, (vol 18, n2 Apr) , P135-145.

53. Webster's

$$
\text { Comprehnsive }
$$

Dictionary.Tridentpress

International(1996), p835

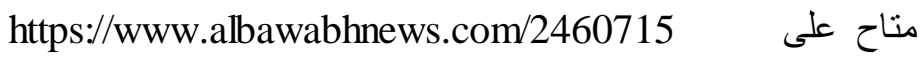

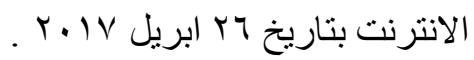

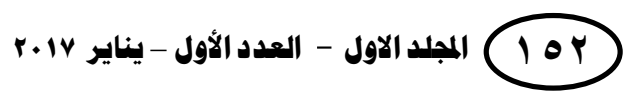

